This report was prepared as an account of work sponsored by an agency of the United States Government. Neither the United States Government nor any agency thereof, nor any of their employees, makes any warranty, express or implied, or assumes any legal liability or responsibility for the accuracy, completeness, or usefulness of any information, apparatus, product, or process disclosed, or represents that its use would not infringe privately owned rights. Reference herein to any specific commercial product, process, or service by trade name, trademark, manufacturer, or otherwise does not necessarily constitute or imply its endorsement, recommendation, or favoring by the United States Government or any agency thereof. The views and opinions of authors expressed herein do not necessarily state or reflect those of the United States Government or any agency thereof.

\title{
Volumetric Radioassay of Lead Bricks Being Considered for Unrestricted Release
}

\author{
R. J. Gehrke \\ S. J. Losinski \\ G. L. Seal
}

January 1995

\section{Idaho National Engineering Laboratory Lockheed Idaho Technologies Company Idaho Falls, ivaho 83415}

\author{
OISTRIBUTION OF THI \\ Prepared for the \\ U.S. Department of Energy \\ Assistant Secretary for Environmental Management \\ Under DOE Idaho Operations Office \\ Contract DE-AC07-94ID13223
}




\section{,}




\section{DISCLAIMER}

Portions of this document may be illegible in electronic image products. Images are produced from the best available original document. 


\begin{abstract}
The hardware, software, and a protocol have been developed for the screening of lead bricks being considered for free release or recycle from the Idaho National Engineering Laboratory. The procedure for measuring the background from a sampling of "clean" lead bricks and for deducing the decision limits (in $\mathrm{pCi} / \mathrm{g}$ ) have been developed. At the decision limit, a radioactive lead brick would be detected with $95 \%$ confidence if it were present. The total and peak efficiencies of a $2.54-\mathrm{cm}$ diameter $\times 2.54-\mathrm{cm}$ high $\mathrm{NaI}(\mathrm{Tl})$ scintillation detector for the counting geometry of the present study were measured with a mixed radionuclide standard and calculated with a Monte Carlo program, CYLTRAN. The deduced decision limit for the counting conditions of the present study were $0.0588 \mathrm{pCi} / \mathrm{g}$ by analyzing the entire spectrum and $0.256 \mathrm{pCi} / \mathrm{g}$ by analyzing the $661-\mathrm{keV}$ peak region for a 900 -second count.
\end{abstract}





\section{CONTENTS}

ABSTRACT $\ldots \ldots \ldots \ldots \ldots \ldots \ldots \ldots \ldots \ldots \ldots \ldots \ldots \ldots \ldots \ldots \ldots \ldots \ldots \ldots \ldots \ldots \ldots$

ACKNOWLEDGMENTS,$\ldots \ldots \ldots \ldots \ldots \ldots \ldots \ldots \ldots \ldots \ldots \ldots \ldots \ldots \ldots \ldots \ldots \ldots$

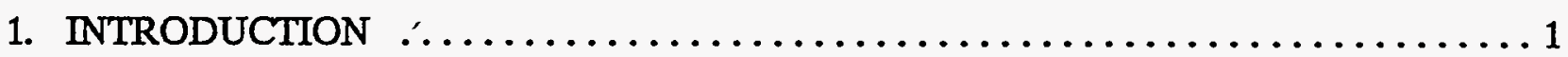

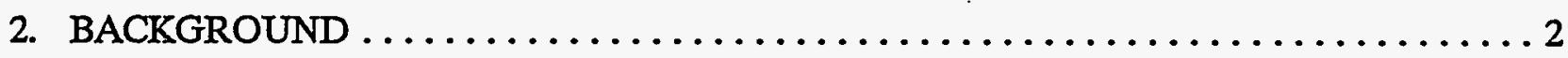

3. EXPERIMENTAL DESCRIPTION $\ldots \ldots \ldots \ldots \ldots \ldots \ldots \ldots \ldots \ldots \ldots \ldots \ldots \ldots$

3.1 Sample Preparation and Experimental Arrangement $\ldots \ldots \ldots \ldots \ldots \ldots \ldots \ldots$

3.2 Data Acquisition and Analysis $\ldots \ldots \ldots \ldots \ldots \ldots \ldots \ldots \ldots \ldots \ldots \ldots$

4. RESULTS AND STATISTICAL ANALYSIS $\ldots \ldots \ldots \ldots \ldots \ldots \ldots \ldots \ldots \ldots \ldots$

5. MONTE CARLO CALCULATION OF DETECTOR EFFICIENCIES $\ldots \ldots \ldots \ldots \ldots$

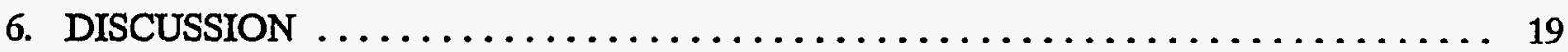

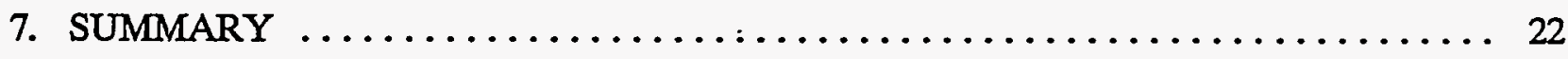

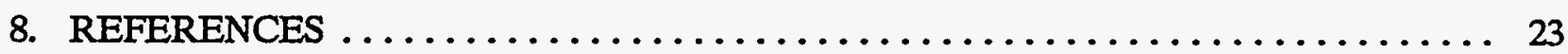

Appendix A - EG\&G Idaho Company Procedures Manual: "Hazardous Material Controls in Radioactive Material Management Areas (RMMA)," Draft Number 8.16 .......... A-1

Appendix B - Calculation of Total and Peak Area Efficiency Using the Monte Carlo Electron

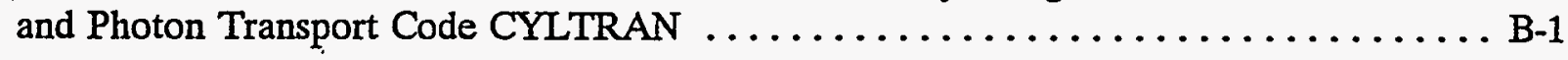

Appendix C - Instructions for the Operation of the Volumetric Lead Brick Contamination

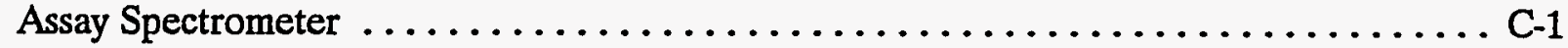






\section{Volumetric Radioassay of Lead Bricks Being Considered for Unrestricted Release}

\section{INTRODUCTION}

Due to a DOE-imposed Hazardous Waste Shipping Moratorium ${ }^{1}$ and the radiological criteria listed in the DOE Radiological Controls Manual, ${ }^{2}$ hazardous materials such as lead must not contain volumetric contamination if they are to be unconditionally released. This report presents a proposed radioassay system and analysis method for verifying that lead is not volume contaminated, and provides results of associated testing and modeling of that system.

A Draft Company Standard Procedure, 3 "Hazardous Material Controls In Radioactive Material Management Areas," has been developed by EG\&G Idaho, which details acceptable analysis techniques and methods for establishing a background envelope in support of the no-radadded standard. This report adapts the approved analysis techniques specifically to lead bricks by defining a background envelope, and a hardware and software configuration, and demonstrates that the proposed radioassay system and procedure can achieve the required sensitivity. Reference 3 has been reproduced in Appendix A for the convenience of the user of this protocol.

The criteria and definitions for this procedure are derived from the "Performance Objective for Certification of Nonradioactive Hazardous Waste." ${ }^{\text {II }}$ Only materials that were received as nonradioactive and have had no radioactivity added by operations at the Idaho National Engineering Laboratory (INEL) can be recycled or disposed as hazardous waste. Any exposure of materials and equipment to radiation or radioactive contamination that has occurred while at the INEL is documented by the use of Form EG\&G-1075; this form is used for all hazardous items that are eligible for eventual shipment to a commercial treatment, storage, or disposal facility or recycling facility prior to shipment to the Idaho Hazardous Waste Storage Facility.

Any item that cannot be certified by process knowledge as "not radiologically contaminated" must be analyzed using an approved analysis process, appropriate for the radionuclides of concern as identified on the EG\&G-1075 form, which is included in Reference 3 (Appendix A of this report). Analysis techniques that have been approved as part of the conditions for lifting the Hazardous Waste Shipping Moratorium are listed in Appendix III of Appendix A. These approved procedures do not presently include a specific analysis for lead bricks.

The investigation reported herein demonstrates the applicability of the proposed experimental equipment and analysis method to the assay of lead bricks and reports achievement of a sensitivity below $1 \mathrm{pCi}$ per gram of lead. This demonstrates the sufficiency of the experimental configuration and radioassay method for screening lead bricks for unrestricted release and recycle. The present method is based upon acceptable analysis techniques specified in Appendix IV of Reference 2 that are applied for the efficient assay of lead bricks for volumetric radioactive contamination. The present study is a follow-up on the work presented in Engineering Design File (EDF) WROC-EDF-237, which proposes free release criteria for INEL lead. ${ }^{4}$ 


\section{BACKGROUND}

Most lead obtained for use at the INEL had no radiological profiles specified nor were any radiological measurements performed upon receipt of the lead. Hence, no baseline information is available. Based upon the study reported in EDF WROC-EDF-237, ${ }^{4}$ the lead at the INEL can be considered similar to what is called "secondary" lead (i.e., recycled at least once).

To establish a statistically significant radiological distribution profile, 20 samples of secondary lead were obtained from RSR Corporation. This company operated the DOE Lead Bank during most of the time a lead contract was in place and provided lead samples from 20 different recycle lots for the study reported in Reference 4. These samples are from approximately 5,600,000 lb of lead extending over a period of 3 to 4 years. The samples received from RSR Corporation were disk-shaped and measured $6.35 \mathrm{~cm}$ in diameter by $1.27 \mathrm{~cm}$ in thickness. The INEL Central Facilities Area Machine Shop produced $\sim 100 \mathrm{~mL}$ of shavings from each lead disk to serve as a sample for radiological analysis.

High-resolution $\alpha, \beta$, and $\gamma$ radiological analyses were performed on these 20 samples of lead from the secondary lead market. No measurable radioactivity at a lower limit of detection of $\sim 10 \mathrm{pCi} / \mathrm{g}$ was found except for the presence of ${ }^{210} \mathrm{~Pb}$, a naturally occurring radionuclide with a 22.3-year half-life that $\beta$ decays and emits a $46-\mathrm{keV} \gamma$ ray. Hence, for the purposes of developing a safe radiological free-release activity concentration, lead can be considered to be a pristine material down to at least $\sim 10 \mathrm{pCi} / \mathrm{g}$ of ${ }^{210} \mathrm{~Pb}$, with essentially no detectable radiological content with the detector system used in the present study since its sensitivity for $\beta$ particles and lowenergy $\gamma$ rays is poor. Therefore, any radiation detected from within the lead brick itself will be regarded as "rad added" and eliminated from unrestricted release for recycle/reuse. 


\section{EXPERIMENTAL DESCRIPTION}

\subsection{Sample Preparation and Experimental Arrangement}

Ten "clean" lead bricks were machined to have bottom holes $(3.334 \mathrm{~cm}$ in diameter by $3.810 \mathrm{~cm}$ deep) that permit monitoring of a portion of the interior of the brick. The size and depth of the hole was chosen so that no potential surface contamination could be directly observed when a small $(2.54 \mathrm{~cm}$ in diameter by $2.54 \mathrm{~cm}$ high) $\mathrm{NaI}(\mathrm{Tl})$ scintillation detector was placed within the hole. Any surface radiation would be attenuated by at least $1.27 \mathrm{~cm}$ of lead. A machined lead shield covered the scintillation detector to reduce exposure of the detector to the ambient background. Figure 1 is a picture of the experimental arrangement with the shielded $\mathrm{NaI}(\mathrm{TI})$ scintillation detector in the hole of the lead brick. The additional shielding provided by the upright bricks on each side of the brick to be counted were not used during the measurements acquired for the present study but may be desirable to further reduce the background when operating in a facility with a higher ambient background. Figure 2 is a drawing of the lead brick in its shielding configuration with the $\mathrm{NaI}(\mathrm{Tl})$ detector in the counting position.

Detailed procedures were developed for operation of a Nomad ${ }^{\mathrm{a}} \mathrm{NaI}(\mathrm{Tl})$ scintillation spectrometer; these included initial setup, calibration of the NaI(Tl) spectrometer, counting the machined lead bricks, and analyzing and archiving the spectral data. The high-voltage setting for the $\mathrm{NaI}(\mathrm{Tl})$ spectrometer recommended by the manufacturer was used for all of the measurements. A plateau curve was measured to confirm the manufacturer's measured curve and to determine the optimum bias. The plateau curve measured in this study is shown in Figure 3. The high-voltage bias should be set approximately $50 \mathrm{~V}$ above the knee of the curve as shown. The threshold is set just above the electronic noise.

The ten machined lead bricks were sequentially counted for 900 seconds; then each brick was removed and replaced by another until 100 counts (10 counts of each brick) were acquired. The 900 -second count times-were chosen as a tradeoff between sensitivity and maximum acceptable time to count one brick. From the analyzed data, this choice of count time achieved a decision limit sensitivity of $<1.0 \mathrm{pCi} / \mathrm{g}$ for potential volumetric radioactive contamination. The procedures used are listed in Appendix $\mathrm{C}$ of this report.

To verify that the gain and zero was stable and that the detector was always operating at the same position on the plateau curve, a $(10.2 \pm 0.5) \mathrm{nCi}{ }^{137} \mathrm{Cs}$ source $4 \mathrm{~mm}$ in diameter was mounted on a stainless steel disk $2.54 \mathrm{~cm}$ in diameter by $0.051 \mathrm{~cm}$ thick. This source was counted after every fifth brick count for a 900 -second live time. A spectrum is shown in Figure 4 . The stroing lowest-energy peak is from the $\mathrm{Ba} \mathrm{K}$ x-rays $(32 \mathrm{keV})$ emitted in the decay of ${ }^{137} \mathrm{Cs}$ (actually emitted in the decay of 2.55 minutes ${ }^{137 \mathrm{~m}} \mathrm{Ba}$ ). The next low-energy peak is from the $\mathrm{K}$ $\mathrm{x}$-rays of lead $(75 \mathrm{keV})$ due to the $\mathrm{x}$-ray fluorescence of the lead brick. The channels in the region of interest selected for the $661-\mathrm{keV}$ peak were checked by the calibration count to ensure that the entire $661-\mathrm{keV}$ peak was being integrated for gross and net counts, and that the number of counts in the gross area of the $661-\mathrm{keV}$ peak remained the same, within statistical fluctuations. The gross and net areas provided a check on the detector total and peak efficiency, respectively.

a. Nomad is a registered trademark of EG\&G Ortec. 


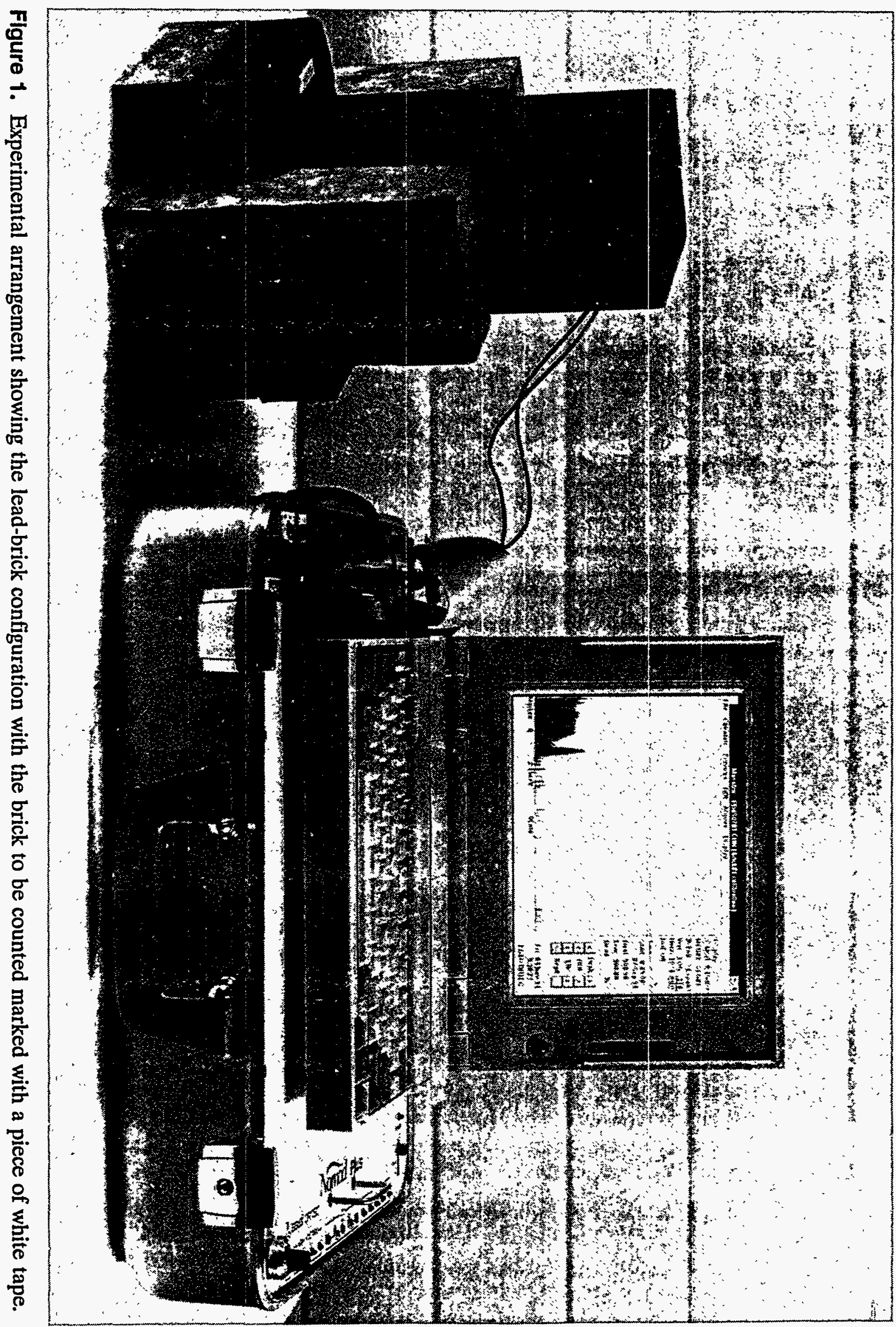




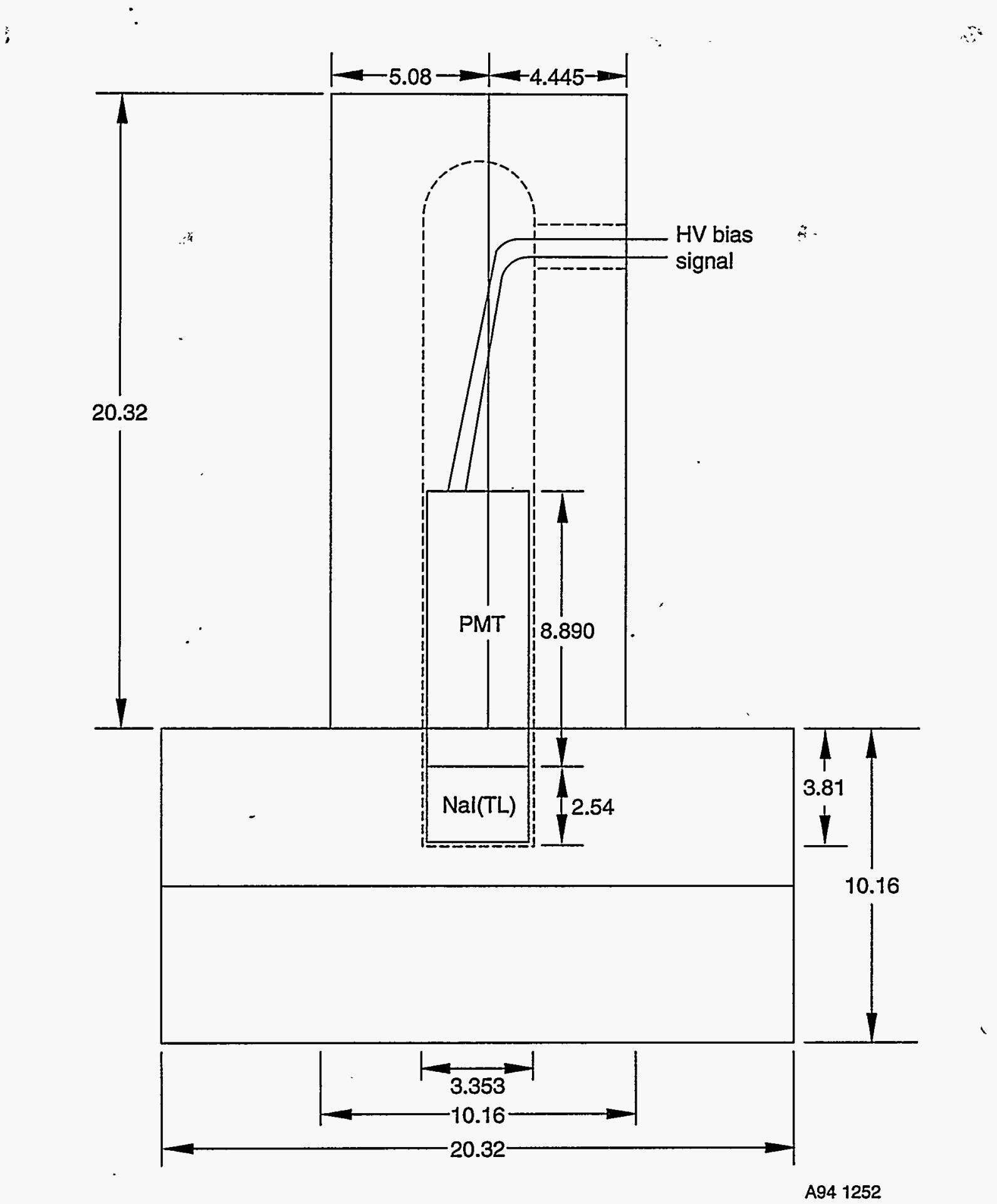

Figure 2. Drawing of the lead brick under test with the lead shielding surrounding it and the $\mathrm{NaI}(\mathrm{TI})$ detector. Dimensions are in centimeters. 


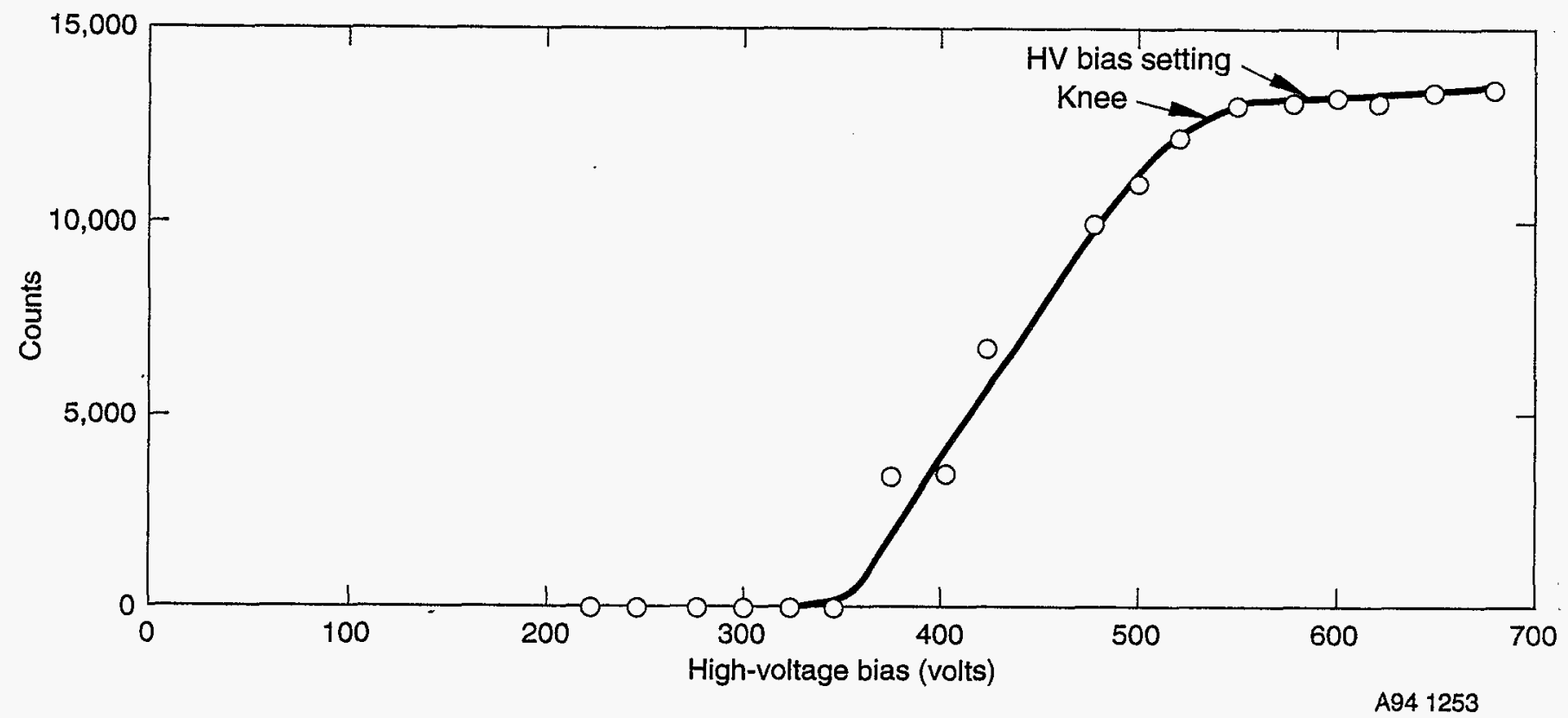

Figure 3. Plateau curve of the $\mathrm{NaI}(\mathrm{Tl})$ scintillation detector acquired with a ${ }^{137} \mathrm{Cs}$ source. 


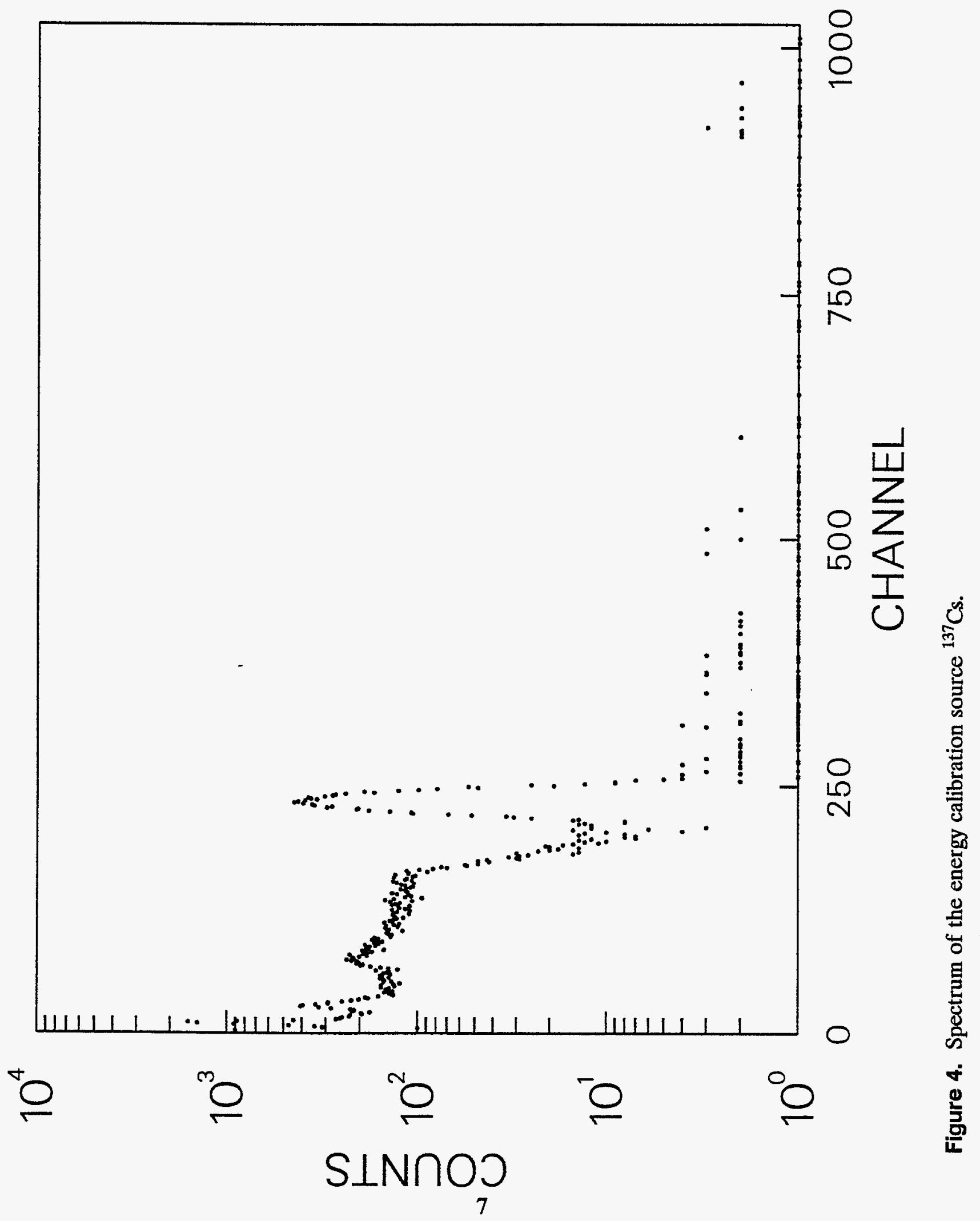


Repeatability of the position of the $661-\mathrm{keV}$ peak also provided a check that the high-voltage bias on the scintillation detector was stable.

A spectrum of an uncontaminated lead brick counted for 900 seconds is shown in Figure 5. A departure from this uninteresting and featureless spectrum is an indication that either a brick is radioactively contaminated or that the noise level has exceeded the lower-level discriminator (see lowest spectral channels for exponentially decreasing counts due to noise). All spectra were labeled and stored on disk. At the end of each day or a series of measurements, the spectra were archived by coping them to a floppy disk.

To establish the adequacy of the experimental arrangement shown in Figure 1, an additional lead brick was set upright on each side of the experimental arrangement where the lead thickness is the least, as shown in Figures 1 and 6 . Additional measurements with this arrangement demonstrated a small decrease $(-5 \%)$ in the total spectral background. This decrease in background count rate did not justify the movement of additional bricks during the measurements taken for this report. However, these additional bricks, and maybe others, may be justified when data are being acquired in an area with a higher ambient background than encountered in these measurements $\left(\sim 1 \mathrm{~s}^{-1}\right)$.

\subsection{Data Acquisition and Analysis}

The data were accumulated with a Nomad multichannel analyzer configured with a 1,024channel conversion gain. Each spectrum was saved and analyzed using the EG\&G Ortec analysis program, MAESTRO. ${ }^{5}$ The total spectrum was integrated by summing the counts, $C_{i}$, in channel i over a region of interest extending from $\sim 10 \mathrm{keV}$ to $\sim 2,850 \mathrm{keV}$ as indicated by Equation (1). The $661-\mathrm{keV}$ peak region was integrated by using the region-of-interest capability of MAESTRO and by recording the gross, $A_{g}$, and net, $A_{n}$, counts in the peak areas. The uncertainty in the gross integrated spectral counts, $s_{g}$, is simply the square root of the integrated counts as indicated by Equation (2). The formulas used by MAESTRO to calculate the gross area and its uncertainties are:

$$
\begin{aligned}
& A_{g}=\sum_{i=L}^{H} C_{i} \\
& s_{g}=\sqrt{\left(\sum C_{i}\right)}
\end{aligned}
$$

The net peak area, $A_{n p}$, as calculated by the MAESTRO software, and its uncertainty, $s_{n p}$ are:

$$
\begin{aligned}
& A_{D p}=\sum_{i=L+3}^{H-3} C_{i}-\frac{B(H-L-5)}{(H-L+1)} \\
& B=\left(\sum_{i=L}^{L+2} C_{i}+\sum_{i=H-2}^{H} C_{i}\right) \frac{(H-L+1)}{6}
\end{aligned}
$$




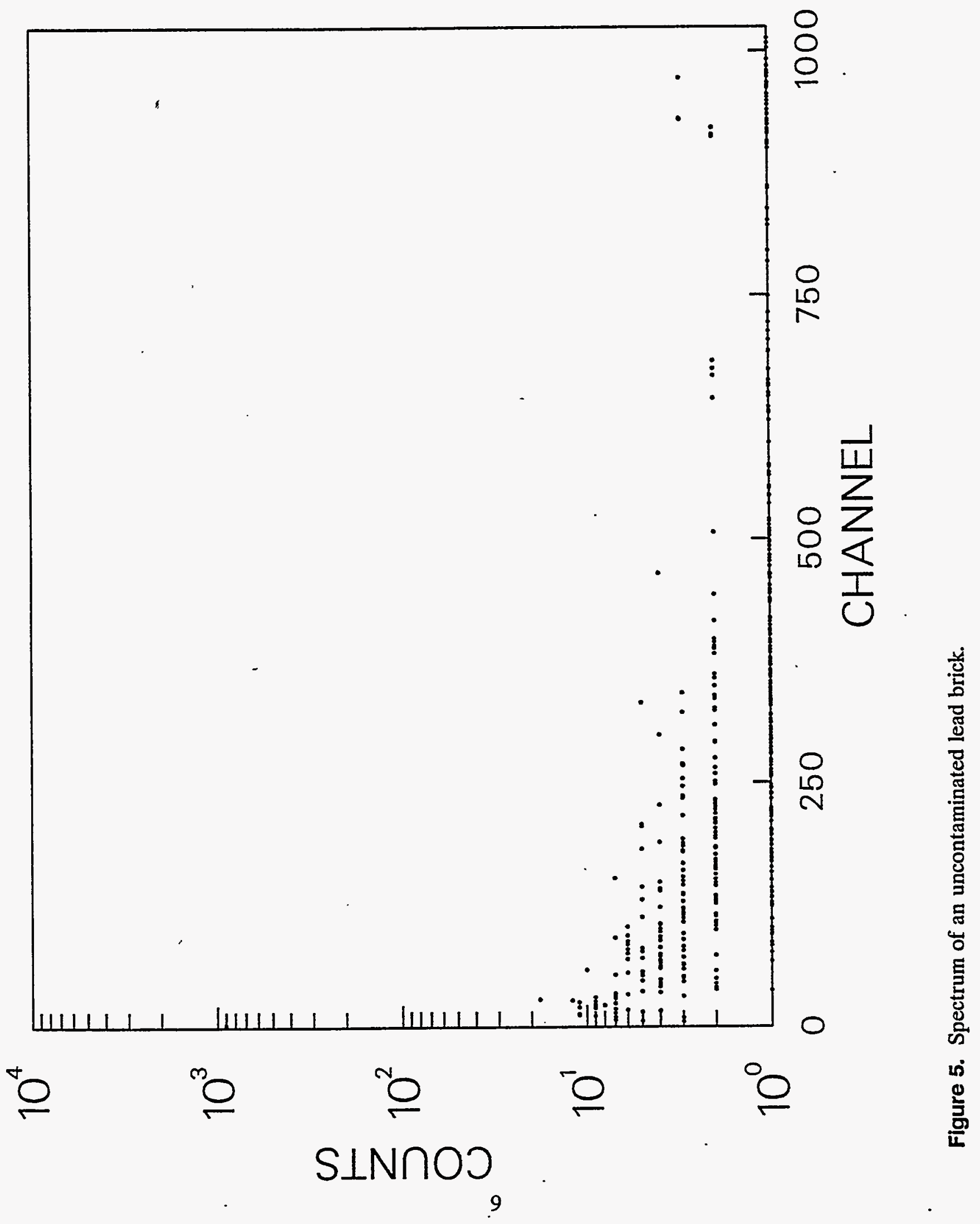




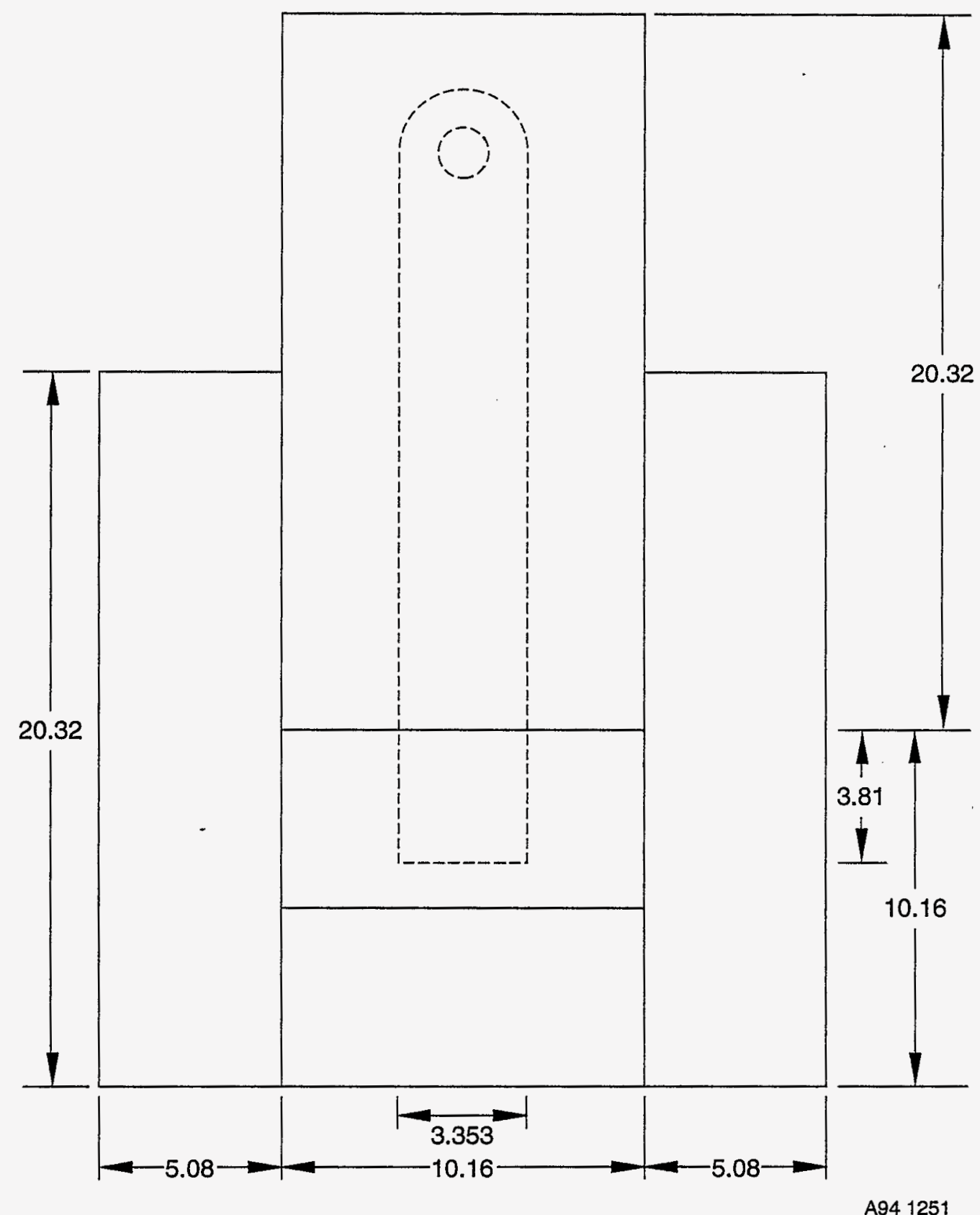

Figure 6. Drawing of the lead brick under test with an additional brick added to each side to further reduce the background. Dimensions are in centimeters. 


$$
s_{n p}=\sqrt{\sum_{i=L+3}^{i=H-3} C_{i}+\left(\frac{H-L-5}{6}\right)\left(\frac{H-L-5}{H-L+1}\right) B}
$$

where

$$
\begin{aligned}
& B=\text { background area } \\
& C_{i}=\text { number of counts in channel } i \\
& L=\text { region-of-interest lower limit } \\
& H=\text { region-of-interest upper limit. }
\end{aligned}
$$




\section{RESULTS AND STATISTICAL ANALYSIS}

After 100 counts were obtained, each of the 10 lead bricks were counted 10 times, an average was taken of the integrated spectral counts, $A(t)$, (from $11 \mathrm{keV}$ to $2861 \mathrm{keV}$ ), and the integrated counts were obtained in the $661-\mathrm{keV}$ region, $A(\mathrm{p})_{g}$. The averages with their standard deviation are $A(t)_{g}=966 \pm 36$ counts, and $A(p)_{g}=70 \pm 10$ counts, respectively. The individual measurements and their averages of the integrated spectral counts for each brick are given in Table 1 to demonstrate that each numbered brick gave results that were statistically the same as those from all bricks $[\mathrm{A}(\mathrm{t}) \mathrm{g}$ above]. The purpose of these measurements is to deduce a decision limit, as defined by L. A. Currie, ${ }^{6}$ and specified in Appendix IV of Reference 3 (see Appendix A of this report). The deduced decision limit applies strictly for detecting ${ }^{137} \mathrm{Cs}$ contamination in the interior of a lead brick but may be extended within limits to other $\gamma$-ray emitting radionuclides as discussed in Section 6.

As stated in Appendix IV of Reference 3, criteria for establishing a decision limit are satisfied "...if the measurement standard deviation, $\mathrm{s}_{\mathrm{m}}$, for the nuclide combination of interest is less than 0.6 of the background envelope $E_{B}$ (discussed in Appendix $V$ of Reference 3), where $E_{B}$ is a set of survey specific values proportional to activity that bound those present in virgin material. ${ }^{b}$ The decision level $L_{d}$, which shall be taken as the larger of $E_{B}$ and $1.65 s_{m}$, will then be $E_{B}$. From the studies reported in Reference $3, \mathrm{E}_{\mathrm{B}}$ is essentially zero (i.e., the counts recorded are not from radiation emitted by the brick). Therefore, the decision limit is determined from the measurement uncertainty. Thus, the confidence of not declaring a radioactive item clean (generating a false negative) is $5 \%$ at $A=L_{d}-1.65 s_{m}$ (nearly zero), $50 \%$ at $A=L_{d}$ (the background envelope), and $95 \%$ at $A=L_{d}+1.65 s_{m}$ (less than twice the background envelope)."

The decision limits in units of ${ }^{137} \mathrm{Cs}$ activity for the present experimental configuration and method was calculated for a $\mathrm{NaI}(\mathrm{Tl})$ detector $2.54 \mathrm{~cm}$ in diameter by $2.54 \mathrm{~cm}$ high and a lead brick sample using a total efficiency and a $661-\mathrm{keV}$ peak efficiency modeled with the Monte Carlo $\gamma$ and electron transport code, CYLTRAN. ${ }^{7}$ This was done to demonstrate that the equipment in the experimental arrangement provided meets a concentration-based sensitivity requirement. ${ }^{4}$ The calculated decision limits for $95 \%$ confidence for the integrated spectrum are:

$\mathrm{L}_{\mathrm{d}}(\mathrm{Bq})=\left[1.65 \sqrt{ } \mathrm{A}(\mathrm{t})_{\mathrm{g}}\right] /(\mathrm{T})\left(\epsilon_{\mathrm{t}}\right)\left(\mathrm{P}_{\gamma}\right)=8.41 \mathrm{~Bq}(227.4 \mathrm{pCi})$

where

$\sqrt{ } A(t)_{g}=s_{g}=\sqrt{ } 966$ for the gross spectral counts.

b. The background envelope value, $E_{B}$, shall be established as the product of the geometric mean and the geometric standard deviation $\mathrm{s}_{\mathrm{g}}$ of the distribution of activities in samples of the virgin material raised to the 1.65 power. Thus, the confidence of not declaring a virgin item radioactive (generating a false positive) assuming a measurement without uncertainty is about $95 \%$.

c. The decision limit is the level at which a true signal can be detected with $95 \%$ confidence. However, $L$. A. Currie uses the symbol $L_{c}$ to define the decision limit and $L_{d}$ to define lower limit of detection. In this report, the lower limit of detection will be represented by the symbol $\mathrm{L}_{\mathrm{D}}$. 
Table 1. Individual averages of total and peak counts for the 10 counts taken of each lead brick. The grand average and its standard deviation for all 100 counts (10 counts of each of the 10 bricks) is $966 \pm 36$.

\begin{tabular}{rrrrrrrrrr}
\hline Brick 1 & Brick 2 & Brick 3 & Brick 4 & Brick 5 & Brick 6 & Brick 7 & Brick 8 & Brick 9 & Brick 10 \\
\hline 1,035 & 1,041 & 1,010 & 1,026 & 961 & 955 & 928 & 945 & 955 & 962 \\
1,024 & 941 & 907 & 962 & 933 & 941 & 964 & 910 & 951 & 970 \\
976 & 1,013 & 939 & 994 & 948 & 969 & 896 & 955 & 966 & 1,020 \\
992 & 1,013 & 1,049 & 960 & 982 & 938 & 945 & 935 & 998 & 997 \\
1,001 & 945 & 974 & 1,017 & 998 & 965 & 944 & 1,012 & 966 & 931 \\
1,019 & 1,006 & 964 & 919 & 953 & 882 & 951 & 949 & 959 & 979 \\
999 & 932 & 910 & 947 & 973 & 890 & 952 & 967 & 942 & 978 \\
1,058 & 986 & 928 & 932 & 985 & 944 & 999 & 930 & 1,003 & 973 \\
961 & 971 & 992 & 956 & 915 & 911 & 1,014 & 1,016 & 974 & 954 \\
977 & 971 & 1,001 & 952 & 945 & 971 & 955 & 926 & 928 & 958 \\
\hline Average: & Average: & Average: & Average: & Average: & Average: & Average: & Average: & Average: & Average: \\
1,004 \pm 30 & $982 \pm 36$ & $967 \pm 47$ & $966 \pm 35$ & $959 \pm 26$ & $937 \pm 32$ & $955 \pm 33$ & $954 \pm 35$ & $964 \pm 23$ & $972 \pm 24$ \\
\hline
\end{tabular}

The calculated decision limits for $95 \%$ confidence for the peak area are:

$\mathrm{L}_{\mathrm{d}}(\mathrm{Bq})=\left[1.65 \mathrm{~s}_{\mathrm{np}}\right] /(\mathrm{T})\left(\epsilon_{\mathrm{p}}\right)\left(\mathrm{P}_{\mathrm{\gamma}}\right)=33.02 \mathrm{~Bq}(892.5 \mathrm{pCi})$

where

$$
\begin{aligned}
& A(t)_{g}=\text { average of the } 100 \text { gross integrated spectral counts } \\
& \sigma_{\mathrm{np}} \quad=\text { measurement uncertainty in the peak area } \\
& P_{\gamma}=\gamma \text {-ray emission probability } \\
& \epsilon_{\mathrm{t}}=0.797 \%=\text { total efficiency } \\
& \epsilon_{\mathrm{p}}=0.145 \%=\text { peak efficiency. }
\end{aligned}
$$

The measurement uncertainty, $s_{n p}$, for the peak area can be simplified from Equation (5) above by assuming that the $C_{i}$ 's are approximately equal. This yields:

$s_{n p}=22.2$ counts. ${ }^{d}$

d. For the present measurements of the $661-\mathrm{keV}$ peak $\mathrm{H}-\mathrm{L}=52$, and the average counts in channel $\mathrm{i}$ is $\mathrm{C}_{\mathrm{i}}=1.23$ in the peak and background regions. 
These equations assume that $\geq 70$ counts have been collected in the energy region of interest. ${ }^{6}$ The determination of the total and peak efficiencies is described in Section 5 with details of the calculation given in Appendix B.

To determine the decision limit as an activity concentration, $\mathrm{L}_{c}(\mathrm{~Bq} / \mathrm{g})$, the activity decision limit is divided by the mass of the lead included in the Monte Carlo model. From the modeled geometry shown in Figure 7 and the density of lead $\left(11.9 \mathrm{~g} / \mathrm{cm}^{3}\right)$, the mass of the lead in the modeled geometry is calculated to be $4,505.7 \mathrm{~g}$.

A second method, advocated by T. L. Rucker, ${ }^{8}$ was used to deduce the decision limit with $95 \%$ confidence for the total ${ }^{137} \mathrm{Cs}$ spectrum and for its $661-\mathrm{keV}$ peak area. Since the counting uncertainty may only be a portion of the total random uncertainty for many radiological analyses, the best way to obtain an estimate of $\sigma_{0}$ (global standard deviation) is to analyze a number of blanks and determine the sample's standard deviation, $s_{0}$. For the present case, $s_{g}=36$ counts $=s_{0}$ for standard deviation of the mean for the integrated spectral counts, $A(t)$, and $s_{\mathrm{gp}}=10$ counts $=s_{o}$ for the standard deviation of the mean of the gross counts in the $661-\mathrm{keV}$ peak region, $\mathrm{A}(\mathrm{p})_{\mathrm{g}}$. If these estimates of $\sigma_{\mathrm{o}}$ are to be used, then a $t$ factor from the "Student's $t$ Table" (included as Appendix D) should be used in place of the $k$ factor used by Currie. Note: The $t$ factor is found in the table in Appendix D at the intersection of the degrees of freedom, $n$, and the desired probability of making a correct decision (95\%). The degrees of freedom value is equal to one less than the number of counts acquired of the "clean" bricks. If the statistical uncertainty in the counts is the only random uncertainty, the Rucker and Currie methods should yield the same result. A larger Rucker decision limit value indicates additional sources of uncertainty. The Rucker method uses the counts and its uncertainty with the background subtracted:

$\mathrm{I}_{\mathrm{D}}=\mathrm{t}^{2}+2 \mathrm{ts}$ or $\mathrm{L}_{\mathrm{d}}=\mathrm{L}_{\mathrm{c}}=\mathrm{ts}_{\mathrm{o}}$

where

$\mathrm{L}_{\mathrm{D}}=$ lower limit of detection

$\mathrm{L}_{\mathrm{d}}=$ decision limit as defined herein

$\mathrm{L}_{\mathrm{c}}=$ decision limit as defined by Currie.

The decision limit for the $661-\mathrm{keV}$ peak area is:

$L_{d}=\left[(t)\left(s_{o}\right)\right] /(T)\left(\epsilon_{p}\right)\left(P_{\gamma}\right)=42.7 \mathrm{~Bq}(1155 \mathrm{pCi})$

The decision limit for the total spectral counts is:

$\mathrm{L}_{\mathrm{d}}=\left[(\mathrm{t})\left(\mathrm{s}_{\mathrm{o}}\right)\right] /(\mathrm{T})\left(\epsilon_{\mathrm{t}}\right)\left(\mathrm{P}_{\gamma}\right)=9.8 \mathrm{~Bq}(265 \mathrm{pCi})$

where

$\mathrm{t}=1.66$ (from table in Appendix D) for 100 sample counts (i.e., 99 degrees of freedom). 


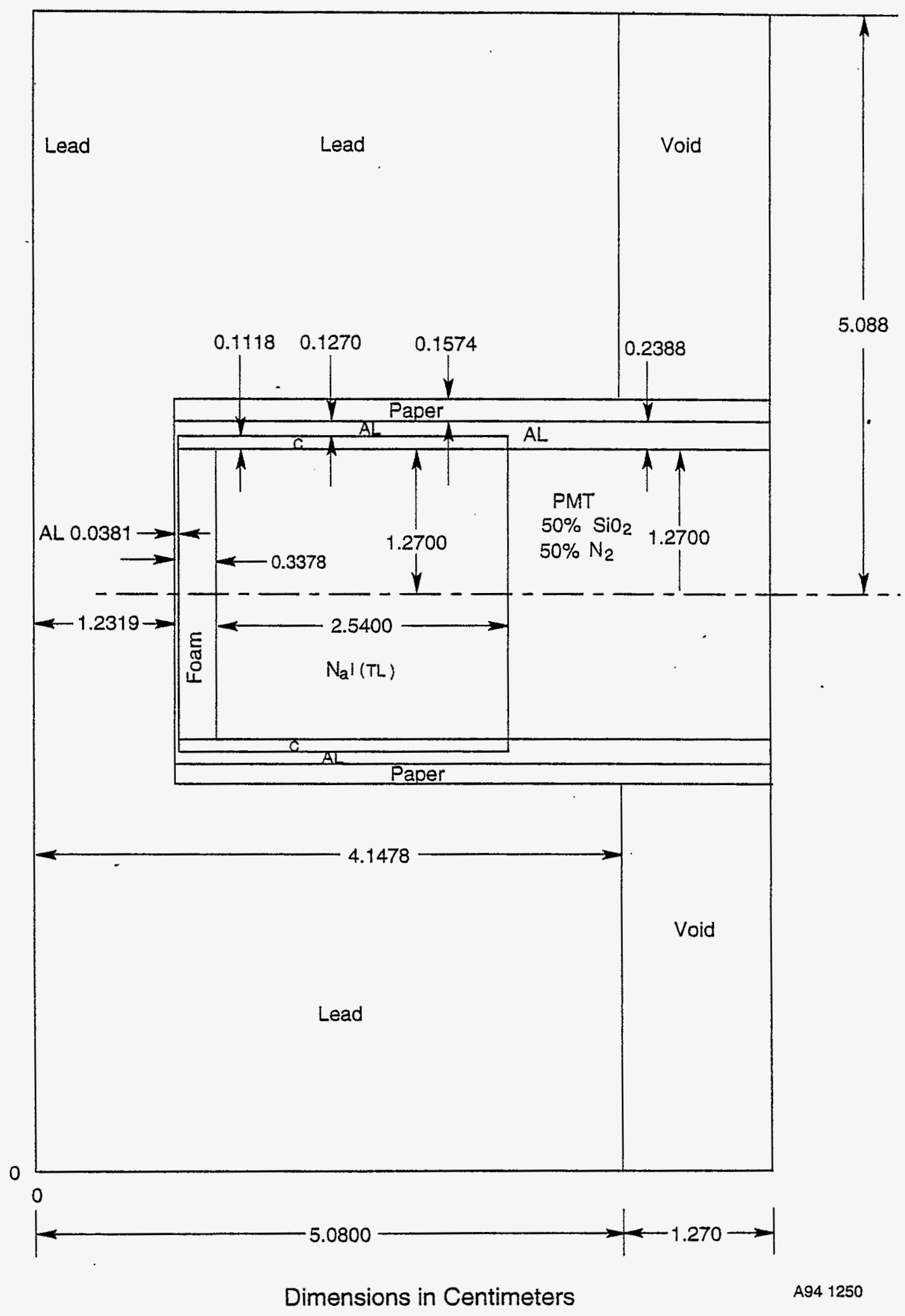

Figure 7. Lead brick modified for CYLTRAN modelling of the efficiency of this geometry for a homogeneously distributed source of ${ }^{137} \mathrm{Cs}$. 
For the total spectrum using Currie's method, the decision limit expressed as an activity concentration is:

$\mathrm{L}_{\mathrm{d}}(\mathrm{Bq} / \mathrm{g})=\mathrm{L}_{\mathrm{d}}(\mathrm{Bq}) / \mathrm{M}_{\mathrm{l}}=0.00187 \mathrm{~Bq} / \mathrm{g}(0.0505 \mathrm{pCi} / \mathrm{g})$.

Using Rucker's method, the decision limit expressed as an activity concentration is:

$\mathrm{L}_{\mathrm{d}}(\mathrm{Bq} / \mathrm{g})=\mathrm{L}_{\mathrm{d}}(\mathrm{Bq}) / \mathrm{M}_{\mathrm{l}}=0.00218 \mathrm{~Bq} / \mathrm{g}(0.0588 \mathrm{pCi} / \mathrm{g})$.

For the peak area using Currie's method, the decision limit expressed as an activity concentration is:

$\mathrm{L}_{\mathrm{d}}(\mathrm{Bq} / \mathrm{g})=\mathrm{L}_{\mathrm{d}}(\mathrm{Bq}) / \mathrm{M}_{\mathrm{l}}=0.00733 \mathrm{~Bq} / \mathrm{g}(0.198 \mathrm{pCi} / \mathrm{g})$

Using Rucker's method, the decision limit expressed as an activity concentration is:

$\mathrm{L}_{\mathrm{d}}(\mathrm{Bq} / \mathrm{g})=\mathrm{L}_{\mathrm{d}}(\mathrm{Bq}) / \mathrm{M}_{\mathrm{l}}=0.00948 \mathrm{~Bq} / \mathrm{g}(0.256 \mathrm{pCi} / \mathrm{g})$.

As can be seen, these two methods give comparable decision limits.

Aware that these decision limits assume that the present background count rate can be maintained, a decision limit goal of $1 \mathrm{pCi} / \mathrm{g}$ is easily achievable with a generous margin of safety with the present system and counting protocol. If the background rate in the field is comparable to that of the present study, the count time could be scaled back up to a factor of two (i.e., 450 seconds) and still maintain a decision limit of $\leq 1 \mathrm{pCi} / \mathrm{g}$. However, it appears prudent to assume that background count rates could easily double or triple when this system is in use in the field and especially in an area where contaminated materials may be stored. Under these circumstances, the decision limit should be remeasured using the more conservative Rucker method presented in this report. 


\section{MONTE CARLO CALCULATION OF DETECTOR EFFICIENCIES}

The $\gamma$ and electron transport code CYLTRAN ${ }^{7}$ was used to model the detector efficiency associated with the counting geometry used in these measurements. CYLTRAN uses cylindrical geometry. Therefore, the two ends of the lead brick were excluded in the modeling process so that the modified brick geometry was a cylinder $10 \mathrm{~cm}$ in diameter with a centered 3.33-cm-diameter hole drilled partially through (3.8 cm deep) from the top as shown in Figure 7. CYLTRAN does not allow making the entire machined lead brick uniformly radioactive, but rather it requires the representation of this geometry by a series of disk-shaped, infinitely thin sources. For this reason, the radioactivity distribution was simulated by a series of 21 disks. In the region where the source disk passes through the $\mathrm{NaI}(\mathrm{Tl})$ detector, two disks were modeled, one the diameter of the drilled hole and one the diameter of the lead brick as shown in Figure 8. The efficiencies obtained from these disks were then combined to give a total and a peak efficiency for only the ring portion of the slice (see Appendix B for calculational details). Each ring efficiency represented an average efficiency of a washer-shaped section $0.25 \mathrm{~cm}$ thick. These ring efficiencies were averaged along with the solid, 5 -cm-radius disks below the hole by weighting each section by its associated mass to yield overall total and peak efficiencies, respectively. The total and peak efficiencies at $661 \mathrm{keV}$ for a source consisting of uniformly distributed ${ }^{137} \mathrm{Cs}$ contamination throughout the brick interior are $0.797 \%$ and $0.145 \%$, respectively.

To validate the accuracy of these CYLTRAN calculations, the total efficiency for a "point" (a 4-mm-diameter source was modeled) ${ }^{137} \mathrm{Cs}$ source was modelled for a source-to-detector distance of $0.02 \mathrm{~cm}$ from the front face of the $\mathrm{NaI}(\mathrm{Tl})$ crystal and found to be $12.4 \%$. This calculated efficiency compares with a measured total efficiency of $13.7 \%$ obtained with a $10.2-\mathrm{nCi}$, 4-mm-diameter source of ${ }^{137} \mathrm{Cs}$ that was prepared for this purpose. The $661-\mathrm{keV}$ peak efficiency was calculated to be $2.88 \%$ versus the measured efficiency of $2.4 \%$. The difference in calculated values to measured values is believed to be due to the uncertainty in the source-to-detector distance and to the uncertainty in the measured peak. Secondary effects resulting from inefficient light and charge collection and from counts lost from or added to the peak area due to limited accuracy in the peak integration contributed to the difference between the measured and calculated peak efficiency. 


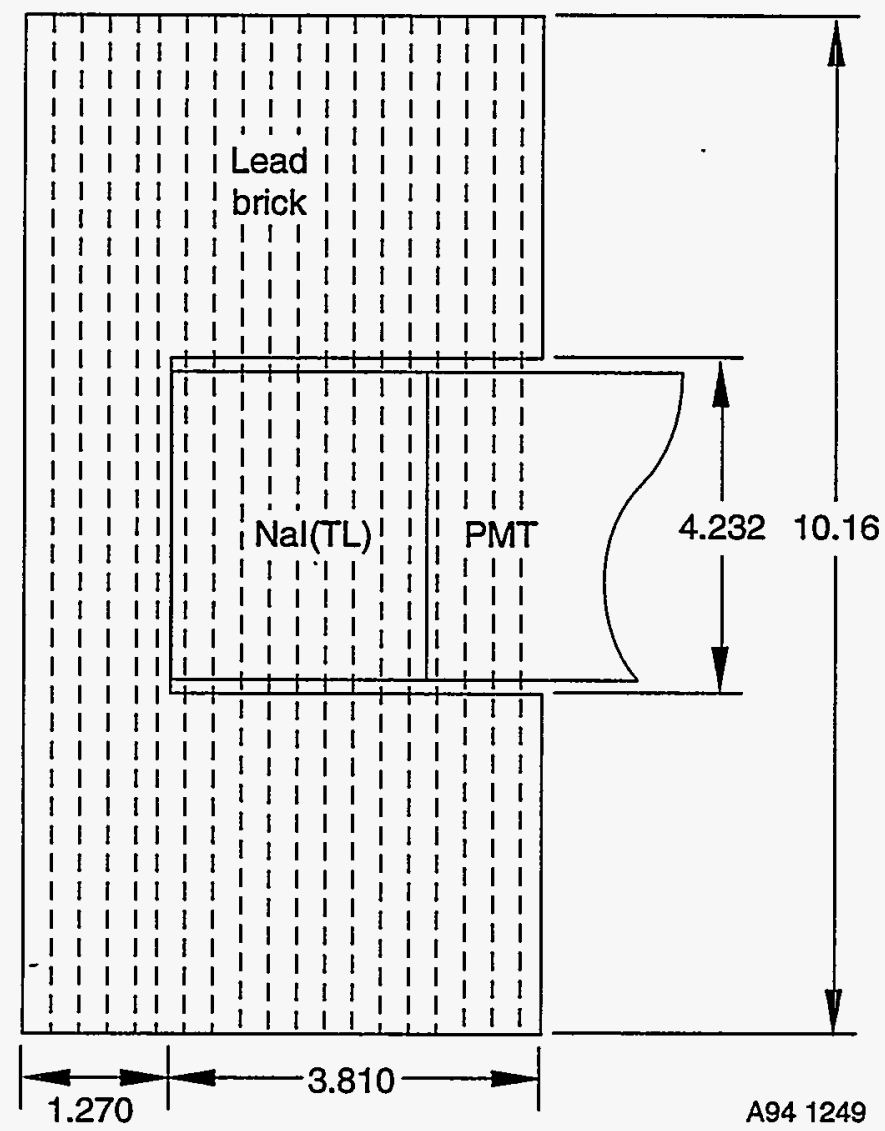

Figure 8. Modified lead test brick divided into slices, typically $0.25 \mathrm{~cm}$ apart, to determine the average efficiency at $661 \mathrm{keV}$. Diameters of $10.16 \mathrm{~cm}$ and $4.232 \mathrm{~cm}$ were modeled with the cnntribution to the efficiency from the smaller slice removed from the large slice. 


\section{DISCUSSION}

From the measurements and calculations performed by the present investigation, the experimental equipment, configuration, and counting procedure have been found to meet (and exceed) the sensitivity requirement of $1 \mathrm{pCi} / \mathrm{g}$ for the release of lead bricks for recycle and unrestricted use. However, it is important to reiterate that the deduced decision limits for a uniformly contaminated brick are only applicable for the experimental conditions of the present investigation and as listed below:

a. These decision limits strictly apply only for ${ }^{137} \mathrm{Cs}$ contamination evenly distributed throughout the lead brick even though extension to other $\gamma$ ray energies and associated radionuclides may be justified.

b. The total efficiency for a $2.54-\mathrm{cm}$ by $2.54-\mathrm{cm}$ diameter $\mathrm{NaI}(\mathrm{Tl})$ detector and point source decreases approximately a factor of two from $450 \mathrm{keV}$ to $2 \mathrm{MeV}$ as shown in Table $2 .^{9}$ Therefore, within a factor of two, a radionuclide emitting one or more $\gamma$ rays, whose sum of emission probabilities are comparable to ${ }^{137} \mathrm{Cs}\left(\mathrm{P}_{\gamma}=0.85 \gamma\right.$ per disintegration) and for $\gamma$ rays greater than $\sim 450 \mathrm{keV}$, should have a decision-level sensitivity within a factor of two of the ${ }^{137} \mathrm{Cs}$ decision level.

c. Any changes in the background counting rate due to changes in the radioactive environment including the room and cosmic contributions will require a reestablishment of the background and the decision level (see Section 4 for this procedure).

If condition (a) is not met, the above deduced sensitivity does not apply and the $\mathrm{L}_{\mathrm{d}}$ may be higher or lower. For example, sensitivity for a contaminated particle right at the bottom of the machined hole will be much higher than for a contaminated particle at the outer edge of the lead brick.

If condition (b) is not met, measured sensitivities could be in error by more than a factor of two and even by more than an order of magnitude. This screening method may, however, be extended to many $\gamma$-ray-emitting radionuclides emitting $\gamma$ rays above $\sim 450 \mathrm{keV}$. ${ }^{\mathrm{e}}$ For example, if the measured decision limit for ${ }^{137} \mathrm{Cs}$ for spectral integration (i.e., gross counts from $\sim 10$ to 3 $\mathrm{MeV}$ ) is $<0.06 \mathrm{pCi} / \mathrm{g}$, the decision limit for these other radionuclides or combinations of them should be $\leq 0.12 \mathrm{pCi} / \mathrm{g}$. The following radionuclides meet these criteria: ${ }^{54} \mathrm{Mn},{ }^{58} \mathrm{Co},{ }^{60} \mathrm{Co},{ }^{106} \mathrm{Ru}$ ${ }^{106} \mathrm{Rh},{ }^{110 \mathrm{~m}} \mathrm{Ag},{ }^{152} \mathrm{Eu}$, and ${ }^{154} \mathrm{Eu}$. However, for radionuclides emitting only $\alpha$ or $\beta$ radiation, $\gamma$ radiation with energies below $450 \mathrm{keV}$, or radionuclides emitting $\gamma$ rays whose sum of emission probabilities is lower than that of ${ }^{137} \mathrm{Cs}$ (i.e., $<0.85 \gamma$ per disintegration), the sessitivity of $1 \mathrm{pCi} / \mathrm{g}$ is not achievable, and this protocol does not apply.

e. The total efficiency from $\sim 500 \mathrm{keV}$ to $2,000 \mathrm{keV}$ for a point source with no intervening attenuating material drops approximately a factor of two for the scintillation crystal of the size used in the present measurements. At the same time as the $\gamma$-ray energy increases, its attenuation in passing through the lead in its path toward the detector decreases. This causes the total efficiency curve for lead brick geometry, as a function of energy, to be slowly varying. 
Table 2. Table of calculated total efficiencies for a $2.54-\mathrm{cm}$ diameter by $2.54-\mathrm{cm}$ high NaI(TI) sodium iodide detector for point source geometry and several source to detector distances.

\begin{tabular}{|c|c|c|c|c|c|c|c|}
\hline$E$ (Mev) & 5.5 & $\begin{array}{l}3.8 \\
7.9 \\
\end{array}$ & 2.04 & 1.10 & .566 & .332 & $\overline{.212}$ \\
\hline $\mathrm{h}(\mathrm{cm}){ }^{2}\left(\mathrm{~cm}^{-1}\right)$ & .127 & .130 & .150 & .200 & .300 & .500 & 1.000 \\
\hline $\begin{array}{l}.001 \\
.200 \\
.300\end{array}$ & $\begin{array}{l}.09550 \\
.06505 \\
.05617\end{array}$ & $\begin{array}{l}.09750 \\
.06642 \\
.05736\end{array}$ & $\begin{array}{l}.11055 \\
.07540 \\
.06512\end{array}$ & $\begin{array}{l}.141330 \\
.09658 \\
.08343\end{array}$ & $\begin{array}{l}.19519 \\
.13408 \\
.11589\end{array}$ & $\begin{array}{l}.27857 \\
.19346 \\
.16743\end{array}$ & $\begin{array}{l}.39742 \\
.28426 \\
.24710\end{array}$ \\
\hline $\begin{array}{r}.500 \\
.700 \\
1.000\end{array}$ & $\begin{array}{l}.04326 \\
.03430 \\
.02523\end{array}$ & $\begin{array}{l}.04417 \\
.03503 \\
.02576\end{array}$ & $\begin{array}{l}. \mathrm{C5OH}_{4} \\
.03975 \\
.02922\end{array}$ & $\begin{array}{l}.06423 \\
.05090 \\
.03738\end{array}$ & $\begin{array}{l}.08922 \\
.07064 \\
.05177\end{array}$ & $\begin{array}{l}.12893 \\
.10194 \\
.07444\end{array}$ & $\begin{array}{l}.19082 \\
.15063 \\
.10934\end{array}$ \\
\hline $\begin{array}{l}1.500 \\
2.000 \\
3.000\end{array}$ & $\begin{array}{l}.01640 \\
.01749 \\
.00653\end{array}$ & $\begin{array}{l}.01675 \\
.01173 \\
.00667\end{array}$ & $\begin{array}{l}.01898 \\
.01329 \\
.00754\end{array}$ & $\begin{array}{l}.021 .23 \\
.01693 \\
.00959\end{array}$ & $\begin{array}{l}.03344 \\
.02328 \\
.01312\end{array}$ & $\begin{array}{l}.04776 \\
.03306 \\
.01845\end{array}$ & $\begin{array}{l}.06925 \\
.04732 \\
.02588\end{array}$ \\
\hline $\begin{array}{r}5.000 \\
7.000 \\
10.000\end{array}$ & $\begin{array}{l}.00294 \\
.00167 \\
.000891\end{array}$ & $\begin{array}{l}.00300 \\
.00170 \\
.000909\end{array}$ & $\begin{array}{l}.00339 \\
.00192 \\
.00103\end{array}$ & $\begin{array}{l}.00430 \\
.00243 \\
.00130\end{array}$ & $\begin{array}{l}.00585 \\
.00330 \\
.00175\end{array}$ & $\begin{array}{l}.00813 \\
.00455 \\
.00240\end{array}$ & $\begin{array}{l}.01111 \\
.00614 \\
.00320\end{array}$ \\
\hline $\begin{array}{r}20.000 \\
50.000 \\
100.000\end{array}$ & $\begin{array}{l}.000248 \\
.0000424 \\
.0000109\end{array}$ & $\begin{array}{l}.000253 \\
.0000433 \\
.0000111\end{array}$ & $\begin{array}{l}.000285 \\
.0000488 \\
.0000125\end{array}$ & $\begin{array}{l}.000359 \\
.0000614 \\
.0000157\end{array}$ & $\begin{array}{l}.000483 \\
.0000823 \\
.0000210\end{array}$ & $\begin{array}{l}.000658 \\
.000171 \\
.0000284\end{array}$ & $\begin{array}{l}.000860 \\
.000144 \\
.0000366\end{array}$ \\
\hline
\end{tabular}

\begin{tabular}{|c|c|c|c|c|c|c|c|}
\hline$E$ (bev) & .152 & .129 & .105 & .081 & $\begin{array}{l}.0295 \\
.0622 \\
\end{array}$ & $\begin{array}{l}.0237 \\
.0484 \\
\end{array}$ &.$\overline{0089}$ \\
\hline$h(\mathrm{~cm}){ }^{0}\left(\mathrm{~cm}^{-1}\right)$ & 2.0 & 3.0 & 5.0 & 10.0 & 20.0 & 40.0 & 600 \\
\hline $\begin{array}{l}.001 \\
.200 \\
.300\end{array}$ & $\begin{array}{r}.47588 \\
-.35922 \\
. .31537\end{array}$ & $\begin{array}{l}.49377 \\
.38702 \\
.34259\end{array}$ & $\begin{array}{l}.49927 \\
.40664 \\
.36370\end{array}$ & $\begin{array}{l}.49966 \\
.41777 \\
.37737\end{array}$ & $\begin{array}{l}.49966 \\
.42157 \\
.38314\end{array}$ & $\begin{array}{l}.49966 \\
.42224 \\
.38492\end{array}$ & $\begin{array}{l}.49966 \\
.42226 \\
.38508\end{array}$ \\
\hline $\begin{array}{r}.500 \\
.700 \\
1.000\end{array}$ & $\begin{array}{l}.24587 \\
.19444 \\
.14054\end{array}$ & $\begin{array}{l}.26962 \\
.21403 \\
.15473\end{array}$ & $\begin{array}{l}.29005 \\
.23179 \\
.16806\end{array}$ & $\begin{array}{l}.30522 \\
.21600 \\
.17937\end{array}$ & $\begin{array}{l}.31261 \\
.25338 \\
.18556\end{array}$ & $\begin{array}{l}.31600 \\
.25717 \\
.18893\end{array}$ & $\begin{array}{l}.31685 \\
.25866 \\
.19069\end{array}$ \\
\hline $\begin{array}{l}1.500 \\
2.000 \\
3.000\end{array}$ & $\begin{array}{l}.08776 \\
.05907 \\
.03148\end{array}$ & $\begin{array}{l}.09607 \\
.06417 \\
.03374\end{array}$ & $\begin{array}{l}.10398 \\
.06900 \\
.03581\end{array}$ & $\begin{array}{l}.17092 \\
.07325 \\
.03761\end{array}$ & $\begin{array}{l}.21485 \\
.07567 \\
.03863\end{array}$ & $\begin{array}{l}.11706 \\
.07705 \\
.03921\end{array}$ & $\begin{array}{l}.11841 \\
.07791 \\
.03956\end{array}$ \\
\hline $\begin{array}{r}5.000 \\
7.000 \\
10.000\end{array}$ & $\begin{array}{l}.01308 \\
.00708 \\
.00363\end{array}$ & $\begin{array}{l}.01377 \\
.00738 \\
.00375\end{array}$ & $\begin{array}{l}.01436 \\
.00763 \\
.00384\end{array}$ & $\begin{array}{l}.01487 \\
.00783 \\
.00391\end{array}$ & $\begin{array}{l}.01515 \\
.00794 \\
.00395\end{array}$ & $\begin{array}{l}.01530 \\
.00800 \\
.00397\end{array}$ & $\begin{array}{l}.01539 \\
.00803 \\
.00398\end{array}$ \\
\hline $\begin{array}{r}20.000 \\
50.000 \\
100.000\end{array}$ & $\begin{array}{l}.000954 \\
.000157 \\
.000397\end{array}$ & $\begin{array}{l}.000973 \\
.000159 \\
.0000400\end{array}$ & $\begin{array}{l}.000986 \\
.000160 \\
.0000402\end{array}$ & $\begin{array}{l}.000996 \\
.000161 \\
.0000402\end{array}$ & $\begin{array}{l}.00100 \\
.000161 \\
.0000403\end{array}$ & $\begin{array}{l}.00100 \\
.000161 \\
.0000403\end{array}$ & $\begin{array}{l}.00101 \\
.000161 \\
.0000403\end{array}$ \\
\hline
\end{tabular}


In any case, it is important to know the radionuclide inventory that could be responsible for contamination. For example, if the bricks have not been in use for a period of 1 year, only radionuclides with long half-lives (e.g., $>100$ days) should be present; if the bricks are from a reactor facility, essentially all radionuclides will be activation or fission products.

Condition (c) requires a constant and known background count rate for the measured decision and lower limit of detection to be valid. Changes in the background count rate will result in a change in the measurement uncertainty and therefore cause a change in the decision limit. For the total spectral count, recalculation of a new decision limit is straight-forward, assuming that at least $\sim 70$ counts are in the integrated spectrum. The decision limit for the total spectral count is proportional to the square root of the factor by which the background increases relative to the measurements in the present report (e.g., an increase of a factor of two raises the decision limit a factor of $\sqrt{2}$ ). This means that the assays should be performed in a facility where the background is constant to avoid frequent redetermination of the decision limit. 


\section{SUMMARY}

The results presented in this report demonstrate the sufficiency of the experimental method and demonstrate that an accurate and documented radioassay method has been developed for the volumetric assay of lead bricks for unrestricted release and recycle. This method is strictly applicable to ${ }^{137} \mathrm{Cs}$ but can be extended to a number of other radionuclides emitting $\gamma$ rays above $450 \mathrm{keV}$ (see partial list in Section 6). This method is based upon acceptable analysis techniques specified in Appendix IV of Reference 3 (see Appendix A of this report) for efficiently assaying lead bricks for volumetric radioactive contamination. The present study is a follow-on of the work presented in EDF WROC-EDF-237, ${ }^{4}$ which proposes free release criteria for INEL lead. 


\section{REFERENCES}

1. Performance Objective for Certification of Non-Radioactive Hazardous Waste, Approved by J. E. Lytle, Associate Director, EM-30, November 15, 1991, Document is dated October 16, 1991.

2. DOE Radiological Controls Manual, June 1992.

3. EG\&G Idaho, Inc., "Hazardous Material Controls in Radioactive Material Management Areas (RMMA)," Company Procedures Manual, No. 8.16, Draft of June 10, 1994.

4. Development of Free Release Criteria for INEL Lead, Engineering Design File Serial Number WROC-EDF-237, June 1994.

5. EG\&G Ortec Inc., MAESTRO II Software Model A64-BI Operator's Manual.

6. L. A. Currie, "Limits for Qualitative Detection and Quantitative Determination," Anal. Chem. 40, (p. 586, 1968.

7. J. A. Halbleib and T. A. Mehlhorn, Nuclear Science and Engineering, 92, p. 338, 1986; and Sandia National Laboratory report SAND 84-0573, 1984; and report SAND 91-1634 (revision of SAND 84-0573).

8. T. L. Rucker, "Practical Determination and Use of Method Detection Limits," to be published in Joumal of Radioanalytical Chemistry, 1995.

9. S. H. Vegors, Jr., L. L. Marsden, and R. L. Heath, Calculated Efficiencies of Cylindrical Radiation Detectors, U.S. AEC Research and Development Report IDO-16370, September 1, 1958. 


\section{Appendix A}

\section{EG\&G Idaho Company Procedures Manual}

\section{"Hazardous Material Controls in Radioactive Material Management Areas (RMMA)," Draft Number $\mathbf{8 . 1 6}$}



EG\&G DAHO, NC. COMPPANY PROCEDURES ILANUAL
TITLE: HAZARDOUS MATERLALS CONTROLS IN RADIOACTTVE MATERIAL MLANAGEMEYT AREAS (RMMLA)

NUMBER: 8.16 DATE:

APPROVED:

EFFECTIVE DATE: 00/00/94

\section{HAZARDOUS MLATERIALS CONTROLS IN RADIOACTIVE MAATERIAL MANAGEMENT AREAS (RMMA)}

\section{PURPOSE AND SCOPE}

1.1 This is the EG\&G Idaho standard procedure to assure that bazardous/toxic wastes shipped from EG\&G Idaho to a commercial treatment, storage, disposal (ISD) or recycling facility that is not licensed to handle radioactivity have no volume radioactive contamination added and no surface contamination above values in DOE 5400.5 as a result of DOE-ID operations. Only those materials that were received as nonradioactive and have had no radioactivity added by INEL operations can be recycled or disposed of as hazardous waste.

1.2 This procedure outlines the system to control, minimize, and document the use of hazardous materials in Radioactive Materials Management Areas (RMMA). It describes the hazardous materials tracking process necessary to ensure knowledge of the status after a material has entered an RMMA. The system provides information that can be used for the certification of hazardous waste as either radioactive or nonradioactive; based on process knowledge, radiological surface survey, and/or sampling and analysis (radioassay). The criteria and definitions for this procedure are derived from the "Performance Objective for Certification of Nonradioactive Hazardous Waste" (Ref 4.1).

1.3 This procedure applies to all materials that have a hazardous component that once generated as a solid waste (Ref. 4.2) is regulated under either the Resource Conservation and Recovery Act (RCRA) or the Toxic Substances Control Act (TSCA) (Ref. 4.3). Hereafter, these materials, will be called hazardous materials, and the waste, after generation, will be referred to in this procedure as hazardous wastes.

1.4 This procedure also provides instructions for use of Form EG\&G-1075, "No Radioactivity Added Certification" (Appendix I). The purpose of the form is to provide nonradioactive certification of individual hazardous waste items and their containers, and to provide radiological data for dose calculations that may be required. This form must be completed for all hazardous waste that is eligible for eventual shipment to a commersial ISD facility or recycling facility prior to shipment to the EG\&G Idaho Hazardous Waste Storage Facility (FWSF). To complete this form, the waste generator must either certify by process knowledge that the waste has had no radioactivity added or provide information about the 
EG\&G DAHO, INC. COMTPAIYY PROCEDURES MAYUAL
TITLE: MATERUAL MANAGEMENT AREAS (RMMLA) NUMBER: 8.16 DATE:

potential sources of radioactive contamination present in the RMMA. "Potentially contaminated" hazardous waste must be certified nonradioactive by the analyst prior to shipment. The surfaces of the hazardous waste containers must be certified clean by a Radiological Control Technician (RCT).

1.5 The measurement techniques and criteria to be used to evaluate whether or not hazardous waste has been volumetrically contaminated with radioactivity by Idaho National Engineering Laboratory (INEL) activities are detailed in Section 2.7 and the Appendices of this procedure. These criteria do not consider whether the radiation hazard is minimal but only if detectable radioactivity has been added.

1.6 All hazardous materials received at the INEL are transferred to the requester for use and are ultimately disposed of at the end of use. A logic diagram outlining the general process for controlling and classifying hazardous material/waste from the time it enters a Controlled Area until it is ready for disposal or recycle is shown in Appendix II. The features of this process and the flow chart are discussed in the following subsections.

2. Procedure

2.1 Before a hazardous nonradioactive material can enter an RMMA, the following requirements must be met:

a. The material and its intended use must be evaluated to determine if any waste that will be generated will be hazardous according to 40 CFR 261, "Identification and Listing of Hazardous Waste."

b. Any waste that will be generated must be expected to meet the INEL Reusable Property, Recyclable Material, and Waste Acceptance Criteria (RRWAC) (Ref. 4.4).

2.2 A background radioactivity level must be determined to support certification that no radioactivity has been added by INEL operations. This can be done by a) treating the background activity as zero, b) by referencing existing information for natural radiation background levels for the material in question and filing the background level for reference, or c) by direct analysis of the virgin (noncontaminated) material. If the material is already in an RMMA option c) will not be possible in which case similar materials may be sampled or one of the other options chosen. 
EG\&G DAHO, INC. COMIPANY PROCEDURES MANUAL
TITLE: HAZARDOUS MATERUALS CONTROLS IY RADIOACTTE MATERIAL MANAGEMIENT AREAS (RMMA)

NUMBER: 8.16 DATE:

If c) is chosen, a sample of the virgin material must be taken using an appropriate procedure from the Environmental Monitoring Unit Standard Operating Procedure for Special Requests (SOP-EM-SR) (Ref. 4.6), a chain of custody form prepared, and a seal applied as described in CP 10.15 "Chain of Custody for Radiological Samples", and the sample archived to document the naturally occurring level of radioactivity in the material.

2.3 To minimize the amount of potentially contaminated material, whenever feasible, the primary container of any material should reside outside of the RMIMA. Only the amount of the material required for immediate use should be transferred into the RMMA. For all hazardous material containers entering the RMMA, the container must be sealed using techniques suggested in CP 10.15 prior to entry and labeled with the correct hazard codes.

2.4 To determine if a hazardous material or waste contains added radioactive contamination as a result of INEL operations, the following steps must be taken each time the material leaves an RMMA:

a. The waste generator must complete Parts 1 to 3 and 5 of Form EG\&G-1075 and submit it, along with the material, to an RCT for a surface survey.

b. The exterior of the closed container must be surveyed for surface contamiation by an RCT as described in CP 10.11 Subsection 2.3 using the criteria in DOE Order 5400.5, Figure IV-1, and the values in the EG\&G Idaho Radiological Control Manual (RCM) Article 422.2a for transuranics, etc. (removable 20-, average 100-, and maximum 300- dpm/100 $\mathrm{cm}^{2}$ ).

c. If surface contamination above these limits is detected, the surface must be decontaminated and surveyed again until the requirements are met.

d. If the waste generator knows by process knowledge the types and levels of radionuclides present in the wastes then it must be managed as mixed waste.

e. It must be determined whether or not the material could be radioactive because of activation by neutrons. The lower dose equivalent limit capable of producing such activation is considered to be $5 \mathrm{mrem} / \mathrm{hr}$ of neutrons, which is the lower level of neutron radiation necessary for a Radiation Area. If the material may be activated, the material must be processed as discussed in Section 2.4.g. 


\begin{tabular}{|c|c|c|}
\hline $3.16 \mathrm{~B}$ & $9 / 27 / 94$ & Page 4 of 20 \\
\hline $\begin{array}{l}\text { EG\&G DAAO, INC. } \\
\text { COMCPANY }\end{array}$ & $\begin{array}{l}\text { TITLE: HAZARDOUS ML } \\
\text { MATERLAL MAN }\end{array}$ & $\begin{array}{l}\text { OLS IN RADIOACTIVE } \\
\text { (RMMMA) }\end{array}$ \\
\hline PROCEDURES MANUAL & NUMBER: 8.16 & \\
\hline
\end{tabular}

f. If the material is in a sealed container that was never opened in the RMMA, the material can be certified as nonradioactive by process knowiedge.

g. If the material has been opened in an RMIMA or exposed to neutrons, capable of causing activation, it will be considered potentially contaminated and the waste generator must complete Parts 4.b) and 5 of Form EG\&G1075.

2.5 When a batch of material is determined to be waste, all of the Forms EG\&G 1075 which were completed when the material was removed from RMMAs must be found.

a. If none are found and the history of the material is short enough that this process would have generated forms whenever the material was in a RMMA, it can be concluded that the material was never in a RMIMA.

If a nonradioactive hazardous material never entered a Controlled Area and can not otherwise become contaminated by INEL operations, the waste generated may be classified as nonradioactive by process knowledge, and a surface survey is not required. If a nonradioactive material enters a Controlled Area but never enters an RMMA and cannot otherwise become contaminated by INEL operations, the waste generated may also be classified as nonradioactive, by process knowledge, however, a surface survey is required prior to leaving the Controlled Area. If the surface survey shows radioactive contamination added by INEL operations, then the waste must be treated as if it entered an RMMA.

If the material was never in an RMMA or Forms 1075 are found which all indicate that the seal was intact ("No" circled in Part 5. under "Internal Contamination?"), then process knowledge that no DOE radioactivity has been added to the material is established.

The generator shall combine information from the existing Forms 1075 onto Parts 1 to 3 and 5 and sign the certification statements Part 4.a) of a Form 1075 indicating that the waste has not been exposed to unconfined radioactive material or neutrons. An RCT shall survey the external container for surface activity as noted in section 2.4.b and complete Part 6. The waste can then be managed as hazardous waste following EG\&G Company Procedures (Cæ) 8.1, 8.2, and 8.3. The waste generator shall ensure that the proper tagging of the material is affixed to the container. 
EG\&G DAHO, INC. COMPANY PROCEDURES MANUAL
TITLE: HAZARDOUS MATERIILS CONTROLS IN RADIOACTTVE MATERLAL MANAGEMENT AREAS (RMMA)

NUMBER: 8.16 DATE:

b. If Forms 1075 are found which indicate the material may be contaminated or the material history is long enough and the generators information weak enough that the process knowledge certification cannot be comfortably signed, the generator shall combine information from the existing Forms 1075 onto Parts 1 to 3 and that from Parts 5 onto Part 4.b. and the material must be analyzed for those nuclides to which it was exposed. The analyst will complete the Form 1075 and determine whether an item can be treated as nonradioactive or must be treated as mixed waste using section 2.7.

2.6 When sufficient hazardous waste has accumulated in the generator's Temporary Accumulation Area (TAA) or Satellite Accumulation Area (SAA), the waste is to be shipped to the HWSF using CP 8.1 subsection 4. This onsite shipment requires completion of a "Shipment Request and Certification", Form ID F-669A. The generator shall attach a copy of each of the Forms EG\&G 1075 and any sample analysis results to the Form D F-669A. The completed forms shall be maintained by personnel associated with the operations of the HWSF. The Form EG\&G-1075 and any sample analysis results shall be maintained on file by the WROC organization for indefinite retention.

2.7 For characterizing waste as radioactive or having no radioactivity added by DOE operations, it is important to know if there was a potential for radioactive contamination of the waste by DOE operations. If process knowledge is sufficient to certify that the waste is radioactive or has no radioactivity added by DOE operations, there is no requirement for analyzing the waste to make a radioactive/no radioactivity added determination. However, if there is a question of whether the waste had radioactivity added by DOE operations or not, then the waste must be sampled and analyzed to determine if radioactivity was added.

a. The generator is responsible to ensure that a representative sample of the waste is obtained for analysis. Sampling shall be performed in accordance with an approved sampling and analysis plan (SAP). This SAP shall be developed by individuals who are qualified and experienced in sampling 'methods. The generator shall contact the Environmental Monitoring Unit of the Environmental Support Group to aid in the development of the SAP. The SAP shall, at a minimum, speciff the sample locations, number and size of samples, precautions necessary to avoid sample contamination, sample preservation methods and analysis required. Statistical processes to be employed for determining sample design and rationale shall be documented in the SAP. The SAP is to be reviewed by the generator and the Environmental Monitoring Unit. It shall be approved by the generator and concurred with by the generator's management. SAPs are to be 
EG\&G IDAEO, INC. COMPANY PROCEDURES MANUAL
TITLE: EAZARDOUS MATERLALS CONTROLS IN RADIOACTIVE NUMBER: 8.16 DATE:

maintained on file by the waste generator management.

b. Because of the wide variety of waste sampling problems at the INEL specific sampling techniques for representative sampling of waste will be developed on a case-by-case basis. Examples of statistical processes that may be used include, but is not limited to, grid sampling based on a random number generator, and systematic grid sampling.

c. A sample must be taken using the approved procedure in the SAP, sealed, and submitted to a laboratory for a radiological analysis along with the sample of the virgin material obtained as described in Section 2.4. Complete the appropriate forms for requesting the analysis service. The container exterior shall be surveyed to discover whether contamination was transferred to the exterior of the container when sampling was done. Decontaminate the exterior as necessary.

Note: If a waste cannot be satisfactorily sampled and analyzed for Fadioactivity it can only be judged on process knowledge. If there is any question whether radioactivity was added by INEL operations then the waste shall be considered radioactive.

d. The sample must be analyzed using an approved analysis process, appropriate for the nuclides of concern in the item as identified on the EG\&G-1075 form. The analysis techniques described in Appendix III, which have been approved as part of the conditions for lifting the Hazardous Waste Shipping Moratorium, should be given preference if they are applicable. Appendix $I V$ describes the process for developing and approving an analysis protocol for situations not amenable to the standard protocols.

e. Hazardous waste shall be treated as mixed waste if a measurement shows that a quantity $A_{\mathrm{mi}}$ related to activity is greater than a survey-nuclide specific decision level, $L_{\mathrm{d}}$. The decision level is the larger of the background envelope $E_{g} e^{+}$., lished for the material or 1.65 times the standard deviation $\sigma_{\text {m }}$ of the particular measurement. The hazardous material, when disposed, shall be considered hazardous waste if the measurement result is smaller than the decision level and mixed waste if the result is larger than that value. If the measurement result is within a factor of 2 of the decision level, it may be redone to determine whether the high value is due to a statistical variation and the lower value used in this determination. 


\begin{tabular}{|l|c|}
\hline EG\&G DAHO, INC. & TITLE: HAZARPOUS MATERIALS CONTROLS IN RADIOACTIVE \\
COMPANY & \multicolumn{2}{|c|}{ MATERIAL MANAGEMENT AREAS (RIMIA) } \\
PROCEDURES MANUAL & NUMBER: 8.16 DATE: \\
\hline
\end{tabular}

The background envelope $E_{B}$ is a set of survey-nuclide specific values, proportional to activity, intended to bound $95 \%$ of those values present in the virgin material. Because different measurement techniques are sensitive to different radiations, the value will depend on the measurement technique used and the suspected nuclides. The process for determination of the background envelope is provided in Appendix V.

f. Once analysis results are available, but before release of the material and container, the analyst must complete Parts 7 through 10 of Form EG\&G1075 and sign the certification statement in Part 10. Analysis results shall be attached to the form and returned to the customer.

g. If, the analysis result is less than the decision criterion, the material inside the container can be discarded as nonradioactive hazardous waste following 2.6 above. If the analysis result is greater than the decision criteria, the material must be considered to be radioactive hazardous waste (mixed waste).

\section{Definitions}

Background Envelope $E_{B}$ - a set of survey specific values proportional to activity which bound $95 \%$ of those present in the virgin material. The basis for determination of the background envelope is provided in Appendix V.

Certification - The action of determining, verifying, and attesting in writing to the qualities of a material or the qualifications of personnel.

Controlled Area - Any area to which access is controlled in order to protect personnel from exposure to radiation and radioactive materials.

Hazardous Material - Any material that can become a hazardous waste when discarded (See hazardous Waste.). For this procedure hazardous material aiso includes TSCA material.

Hazardous Waste - Any waste defined as hazardous in 40 CFR Part 261. The radionuclides of source material, special nuclear material, and byproduct material as defined by the Atomic Energy Act (AEA) of 1954, as amended, are specifically excluded from the term hazardous waste. The hazardous components of waste mixed with the radionuclides of source, special nuclear, or byproduct material are not excluded from the term hazardous waste. For this procedure hazardous waste also includes TSCA waste (40 CFR761). 
EG\&G DOAHO, INC. COMPANY PROCEDURES IVANUAL
TITLE: HAZARDOUS MATERIALS CONTROLS IN RADIOACTTVE MATERIAL MANAGEMENT AREAS (RNIMA)

Mixed Waste - Any waste containing both radioactive and hazardous components regulated by the AEA and RCRA, respectively. The term "radioactive component" refers only to the actual radionuclides dispersed or suspended in the waste substance.

Process Knowledge - Knowledge of the process or materials involved in the generation of the waste. An individual who is cognizant of the activities, conditions, and procedures resulting in and governing the waste, and is qualified to make the decision as to whether the waste is nonradioactive, potentially contaminated, or radioactive may make a process knowledge decision.

Radioactive Materials Management Area (RMMA) - An area where the potential for radioactive contamination exists due to the presence of unencapsulated or unconfined radioactive material or because of the presence of sufficient levels of neutrons to produce activation. Naturally-occurring radioactive materials (NORM) are exempt from this determination unless DOE operations have caused the NORM to be concentrated. RMMAs are posted by a RCT following CP 10.10 .

Radioactive Waste - Any waste managed for its radioactive content, which is not otherwise regulated for that radioactive content (e.g., regulated by the Clean Air Act (CAA), Clean Water Act (CWA) etc.). If a material was received as nonradioactive, any resulting waste is not a radioactive waste if it meets the following conditions:

a. Contains no measurable increase in radioactivity (at a statistically defined confidence interval) above background in volume or bulk resulting from $D O E$ Operations. except for wastes specifically exempted by EPA, DOE, or NRC regulations (e.g., 10 CFR 20.2005); and,

b. Contains no surface radioactivity above limits established in the EG\&G Idaho Radiological Control Manual, Table 2-2 and DOE Order 5400.5, Figure IV-1.

\section{REFERENCES}

4.1 "Performance Objective for Certification of Non-Radioactive Hazardous Waste," Approved by J. E. Lytle, Associate Director, EM-30, Novermher 15, 1991, Document is dated October 16, 1991.

4.2 40 CFR 261, Identification and Listing of Hazardous Waste.

4.3 40 CFR 761, Toxic Substances Control Act.

4.4 INEL Reusable Property, Recyclable Materials, and Waste Acceptance Criteria 
EG\&G DAHO, INC. COIMIPANY PROCEDURES MIANUAL
TITLE: HAZARDOUS IMATERIAIS CONTROLS IN RADIOACTIVE MLATERIAL MANAGEMENT AREAS (RIMTMLA)

NUMBER: 8.16 DATE:

(RRWAC). DOE/D-10381, Rev. 1 February 1994.

4.5 EG\&G Idaho Company Procedures Manual, Sections 8.1, 8.2, 8.3, 8.6, 10.10, $10.11,10.15$, and 11.2.

4.6 Environmental Monitoring Unit Standard Operating Procedure for Special Requests (SOP-EM-SR)

4.7 Form EG\&G 1075, "No Radioactivity Added Certification" Appendix I.

4.8 EG\&G Idaho Radiological Control Manual.

4.9 Form ID F-669A, "Shipment Request and Certification"

4.10 Form EG\&G 669, "Generator's Hazardous Waste Material Profile Sheet."

4.11 DOE Order 5400.3, Hazardous and Radioactive Mixed Waste Program.

4.12 DOE Order 5400.5, Radiation Protection of the Public and the Environment.

4.13 DOE Order 5820.2A, Radioactive Waste Management. 


\begin{tabular}{|l|c|}
\hline EG\&G DAHO, LNC. & TIILE: HAZARDOUS MATERLALS CONTROLS IN RADIOACTIVE \\
COMPANY & MATERLAI MANAGEMENT AREAS RMMA) \\
PROCEDURES MANUAL & NUMBER: $8.16 \quad$ DATE: \\
\hline
\end{tabular}

\section{APPENDIX I (Page 1 of 2) \\ FOAN EG2G-1075 \\ (Rev. ars) \\ NO RADIOACTIVITY ADDED CERTIFICATION}

Purpose: This form provides certification that no radioacjivity was added by EGaG operations to individual waste or materials and their containers that are eligible for unrestricted release of site. This form will be maintained by the Waste Reduction Operation Complex organization for potential review by auditors.

1. Waste Name:

2. Container Identifier:

3. Document No:

\section{Generator Process Knowledge Certification}

4. Sign one of the following.

a) Based on my knowiedge of the history of this material and the information in Section 5 below, l certify, by process knowledge. that this material has not been exposed, as a resuit of EG\&G operations, to uncenfined radioactive material or to sources of activating liux.

Generator Name: (Printed) Signature: Date

b) Based on the information in Section 5 below, this material may possibly be contaminated and thus needs to be certified by analysis. Analysis concem B/y pure $\beta \quad \alpha$

Generator Name: (Printod) Signature: Date

5. Did the material enter an area where it could have been contaminated with radioactivity? Yes No

(If the answer is Yes, complete the characterization below)

Exit Date

$$
\begin{aligned}
& \text { Internal Contamination? } \\
& \text { Circle One }
\end{aligned}
$$

$\begin{array}{ll}\text { Maybe No } & \text { Naybe } \\ \text { No } \\ \text { Maybe No }\end{array}$

Contaminant Likely Circle all applicabie ones

B/y pure $\beta \quad \alpha$

Bhy pure $\beta$ a

By pure $\beta$ a

\section{Surface Survey Certification}

6. I certify based upon results of approved surface survey methods, that the external surfaces of this material meet the release levels in the EG\&G Idaho Radiological Controls Manual for removable and total surface contamination.

RCT Name: (Printed)

Signature: $-$ Date

\section{Analysis Certification}

7. Material Analysis technique

8. Use one of the foilowing.
a. Virgin exact sample $A_{8}$
$\sigma_{e}$ $L_{c}=A_{g}+1.65\left(\sigma_{B}{ }^{2}+\sigma_{M}{ }^{2}\right)^{1 / 2}$
b. Background envelope $\varepsilon_{0}$ Basis Documen: $L_{d}=$ the larger of $E_{8}$ or $1.65 \sigma_{M}$

9. Measurement result $A_{M}$ $\sigma_{M}$ Decision Level Lo

Mark A or $B$

A. $A_{M}>L_{d}$

8. $A_{M}<4$

10. Material has no radioactivity radicactivity added by EG\&G operations based on these analysis results. 


\begin{tabular}{|c|c|}
\hline $\begin{array}{l}\text { EG\&G DDARO, INC. } \\
\text { CONOPANY }\end{array}$ & $\begin{array}{l}\text { TITLE: EAZARDOUS WLATERLALS CONTROLS IN RADIOACTIVE } \\
\text { MLATERIAL MANAGEIMENT AREAS (RMTILA) }\end{array}$ \\
\hline PROCEDURES MLANUAL & NUMBER: 8.16 \\
\hline
\end{tabular}

FOPM EGSGIOTS and

\author{
APPENDLX I (Page 2 of 2)
}

Definition: Radioactive Material - Any material that is determined to be contaminated, or suspected of being contaminated, with radioactivity. NORM is exempt from this radioactivity determination if it is not present in concentrations greater than the levels normally found in the environment. Radioactive material also includes activated material, sealed and unsealed sources, and material that emits radiation.

\title{
INSTRUCTIONS
}

Entry an Form

Form Initiator

1. Enter the common name of the material that is included in this container. Example: motor oil

2. Enter the unique Identifier of the container that this form is addressing.

3. Enter the document No. that will be used for shipping this material to a location where it can be released offsits for unrestricted use. This entry is optional, and will be used at the discretion of the form generator.

Note: Complete 4.2. or 4.b. as appropriate.

4.a. Enter the name of the person certifying that the material has not been exposed to radioactive material as a result of INEL operations. (Print and sign) Enter date that the certification was made. This certification is based on negative answers to $\mathrm{m5}$.

4.b. Enter the name of the person indicating that the material may have been exposed to radioactivity and thus requires analysis. (Print and sign) Enter date of signature. Identify the analysis concem after considering the information in item $\# 5$.

5. Enter the date that the material was taken from an area where it could have been contaminated by radioactivity, in a format that follows month, day, year. (Example: 03-14-91)

Indicate by cirding either Maybe or No if internal contamination was possible while in an area where it could have been contaminated with radioactivity.

If Maybe has been circled, identify the class of contarainant that was likely to have been encountered by circting that contaminant. This information should be available from the AMMA gosting or the Fadiological Control Technician (RCT) familiar with the area of concern.

6. Enter the name of the RCT that is certifying that the Surface Survey is acceptable. (Print and sign) Enter date that the RCT signed the certification.

Note: items 7.10 must be completed by the person (Trained and certified on that analysis tectnique) who conducts the analysis.

7. Materiai: Identify the class of materials this belongs to. This will be used in grouping and recovering information for the background envelope.

Analysis Technique: The response here must be appropriate for detecting the analysis concem identified on itern 4.b. Moreover it must be a technique approved as per the protocol in the CPM Secion 8.16. Appendix IV. Identity it by the name and number for the analysis approval.

8. One of two choices must be user:. Thoice a) will be more restrictive and is used if an exact surrogate virgin sample is provided. Choica b) is used if the item does not have an exact surrogate or could have come from several samples or is a mixture of several substances. In both cases the formula for a decision level $L_{d}$ is stated which can be calculated from the ather values of $A_{g}, \sigma_{g}, E_{8}, A_{M}$ and $\sigma_{M}$. This value of $L_{d}$ should be entered in the blank in item $\$ 9$.

If Choice $(b)$ is used, find the background envelope from the database of existing intomation and enter it on the form.

9. Analyze the materials and any virgin samples. Fiocord the measured activities and the associated calculated standard deviation.

Mark A or 3 depending on whether the measured activity is greater than or less than the decision level.

10. If the measured activity is greater than the decision level, the material contains acted radioactivity. If the raeasured activity is less than the decision level, no radioactivity was added and the material can be certified as nonradioactive by radiological analysis.

Enter the name of the person that performed the radiglogigal analysis and has therefore generated that data that determines whether radioactivity is present in the sample Ponnt and sign) Enter date that the analyst signed the certification. 
EG\&G DAAO, INC. COIYIPANY

PROCEDURES MLAYUAL
TILE: EAZARDOUS WLATERIALS CO:YTROLS LY RADIOACTIVE MLATERIAI MAYAGEMTENT AREAS (RHIMIA)

NUMBER: 8.16 -DATE:

APPENDIX II (Page 1 of 1$)$

HAZARDOUS MLATERIALNWASTE CONTROL SYSTEMI LOGIC DIAGRAMI

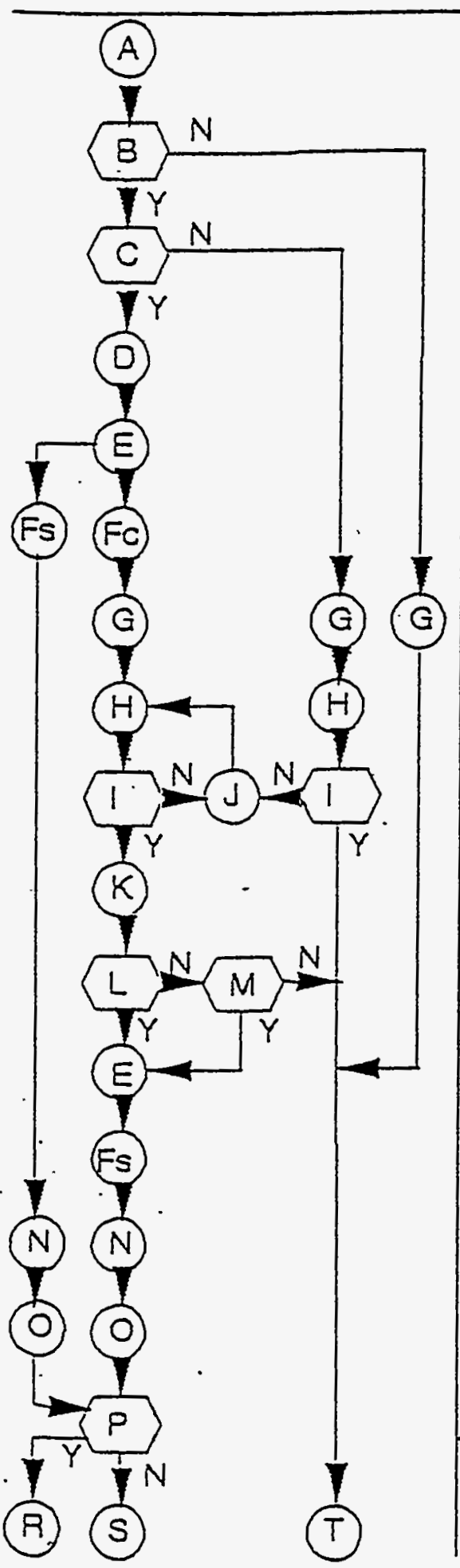

\section{ACTMITIES}

A Hezardous weste or material

$\mathrm{B}$ Will it enter a controlled area?.

(CP 8.16, 2.5.a)

C Will it enter an RMMA?

(CP 8.16, 2.5.a)

D Evaluate to determine if any waste generated will be hazardous and if it will meet the

INEL RRWAC. (CP 8.16, 2.1)

$E$ Obtain sampie (CP 8.16, 22 \& 2.7.a, b and $c$ )

Fs Label and seal sample and prepare chain-ofcustody form (CP 10.15, 2; CP 8.16, 2.2)

FC Label and seal container (CP 10.15, 2; CP 8.16, 2.3)

$G$ Use

H Survey exterior suriaces

(CP 10.11,2.1.2; CP 8.16, 2.4.b)

1 Does it meet EG\&G requirements?

(CP 10.11, 21.2; CP 8.16, 2.4.b \& 2.5.a)

$\checkmark$ Decontaminate exterior surfaces (CP 10.11, 6.1.1.a)

$K$ Remove fom RMMA (CP 10.11, 2 ; CP 8.16, 2.4)

$L$ Was the seal broken? (CP 8.16, 2.4.f \& g)

$M$ Could there be radioactivity because of activation of the waste (i.e. neutrons) (CP 8.16, 2.4.e)

$N$ Analyze (CP 8.16, 2.2, 2.5.b \& 27.d)

0 Document results ( $C P$ 8.16, 2.7.f)

P Has radiation been added?

- (CP 8.16, 27.e and g)

A Manage as redioactive mixed waste (CP 8.16, 2.7.8)

S Certiny as nonradioactive hazardous waste by radiological analysis (CP 8.16, 2.7.f and g, EG\&G-1075)

T Ceruffy as nonradioactive hazardous waste by process knowledge (CP 8.16, 25.a; EG\&G-1075) 


\begin{tabular}{|l|c|}
\hline $\begin{array}{l}\text { EG\&G DAHO, INC. } \\
\text { COMOPANY } \\
\text { PROCEDURES MLANUAL }\end{array}$ & $\begin{array}{c}\text { TITLE: HAZARDOUS MIATERIALS CONTROLS IN RADIOACTIVE } \\
\text { MLATERIAL MANAGEMIENT AREAS (RMIMLA) } \\
\text { NUMBER: } 8.16 \quad \text { DATE: }\end{array}$ \\
\hline
\end{tabular}

\section{APPENDIX II (Page I of 3)}

\section{APPROVED SCREENTNG METHODS TO DETERINIE THAT "NO RADIOACTIVITY. WAS ADDED BY DOE OPERATIONS"}

The approved screening methods for certifiing that hazardous waste has not been contaminated in volume or bulk by radioactivity added by DOE operations are summarized below. Appendix IV describes the process for developing and obtaining approval for an analysis method for samples that are not compatible with these or other approved screening methods.

The requester of the analysis must obtain an RMD Analyses Request Form (attached) and properly fill it out. Prior to sending a sample to the lab for determination that no. radioactivity was added, the likely type of radioactivity in the waste $(\beta / \gamma$, pure $\beta$, or $\alpha)$ must be determined. This information which should appear on the RMMA posting should have been entered on the EG\&G-1075 form when the waste was removed from the RMMA. In "Block I - Type of Analysis Requested" check the appropriate "Screening Methods" required based on the determination of the likely radioactivity contaminating the sample. If $\alpha$ is circled on EG\&G-1075, check "Alpha". If pure $\beta$ is circled on EG\&G-1075, check "Beta." If $\beta / \gamma$ is circled on EG\&G-1075, check "Gamma".

Circle "Haz. Waste Form 1075" as the required "Report Type" to designate that the analysis is being made for a "no radiation added" determination. Be certain that a detailed description of the "Sample Type" is entered on the form. The lab will analyze the sample by the appropriate method depending on the type of analysis requested and the sample matrix. . The sample, Analyses Request Form, and EG\&G-1075 form are then sent to the lab. The EG\&G 1075 form must be sent to the lab with the sample because the analyst must fill out and sign the "Analysis Certification" section of the form when the analysis is complete.

A summary of the screening methods that will be used to determine that."no radioactivity was added" follow:

Method 1- RAP 2, "Gross Alpha-Beta Determination of Aqueous Solutions" Alpha-Beta Proportional Counting of clear liquids that can be evaporated and only contain small quantities of dissolved solids or insoluble material.

Sample size: $1 \mathrm{ml} \quad$ Counting Time: 100 minutes

Comments: If elevated alpha activity is present, the SS plate should be counted in an alpha spectrometer to either identify the alpha emitter present or to determine if the "alpha" activity present (from the proportional measurement) was due to crosstalk from the beta 
EG\&G DAHO, EIC. COIMPALYY PROCEDURES MIANTAI
TIILE: HAZLRDOUS MLATERIALS COYTROLS N RADIOACTTVE WIATERLAL MAYAGEIVENT AREAS (RYMIA)

\section{APPENDIX III (Page 2 of 3 )}

channel. If the beta activity from this screening analysis is statistically positive, the sample may be rerun using analytical methods specific for the nuclides of interest (i.e. Sr-90, ivi-63, $\mathrm{Fe}-55$, etc.). The results of gross beta screening methods will not be interpreted in terms of activity.

MIethod 2 Radiochemistry on all other sample types: siliceous, non-siliceous, organic, inorganic, etc.

Sample Size: $\quad 0.5$ to $1 \mathrm{~g}$ or $\mathrm{ml} \quad$ Counting Time: 100 minutes

Procedure: RAP 14, "Sequential Determination of the Actinides in Small Environmental Samples" using high resolution alpha spectrometry or RAP 8, "Strontium-89/90 Determination of Soil and Other Solids"; RAP 10, "Ytrium-90 Determination" using proportional counting.

Method 3 - Gamma-ray spectrometry (HPGe or GeLi)

Counting Time: 20 minutes

Procedure: RNIL-6, "RMIC Procedure for Counting and Analysis of Gamma-ray Emission of Radionuclides in Liquid Samples" for $540 \mathrm{ml}$. of liquid in a poly bottle with a small neck and a screw top lid.

or RMIL-3, "RMC Procedure for Counting and Analysis of Soil, Vegetation and Mammal Samples" for approximate sample sizes $500 \mathrm{~cm}^{3}$ (soil $600 \mathrm{~g}$, veg. $170 \mathrm{~g}$ ) and $120 \mathrm{~cm}^{3}$ (Soil $140 \mathrm{~g}$ ). 
EG\&G D.LAO, EC.

COMLPANY

PROCEDTRES ILATUAL

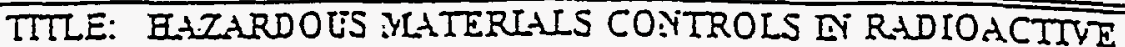
MLATERIII WLAYAGEIYEIYT AREAS (RRYMIA)

NUREER: 8.16 DATE:

\section{APPENDIX III (Page 3 of 3)}

RADARON MEASUGEMENTS AND'OEYEOFWEMT RNALYSES REOUEST FOEM

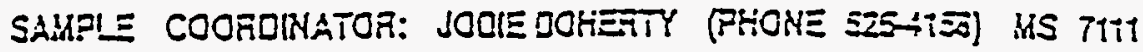

GROJECT NAULE REOUESTNG GROUP TOTAL \# SAMFIES HP SUAVEY $=$ ? SUEMIITE EY TECHNICAL CONTACT SEND RESULTS TO

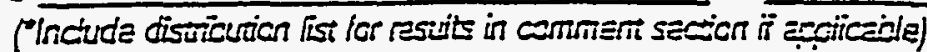
SOW/TOS CiAAREE :

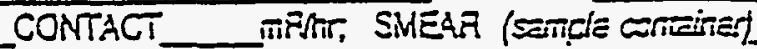
ET ET EnT MVS $\operatorname{cin} / 700 \mathrm{c \pi} 2$ ETT Wiv MS

SAMFLE DISPOSAL CONTACT ins

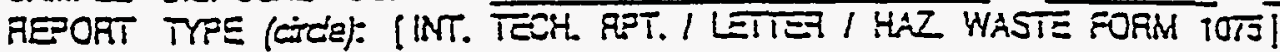
ACTVITY UNITS (UCi, $q C$, ete) VOLUME UNTS (mL $L$ g, Ete)

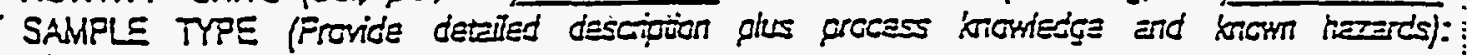



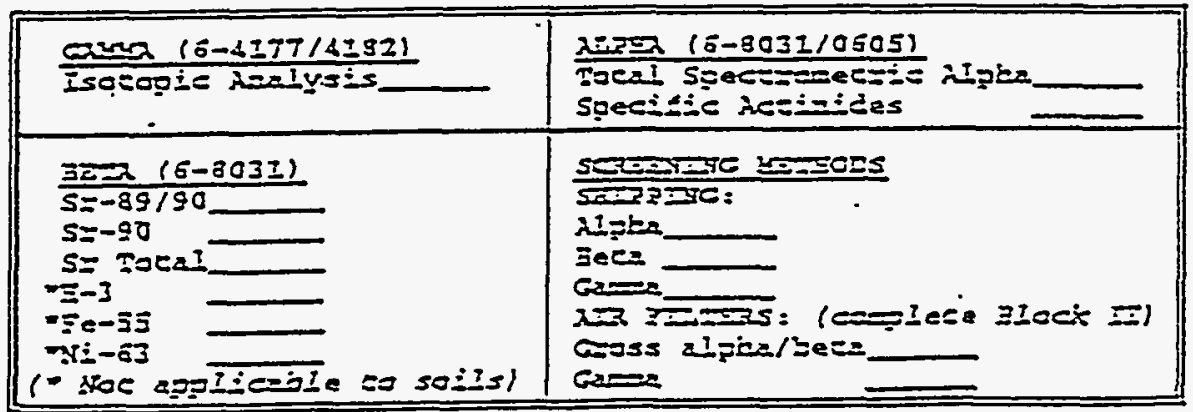

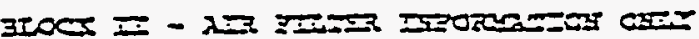

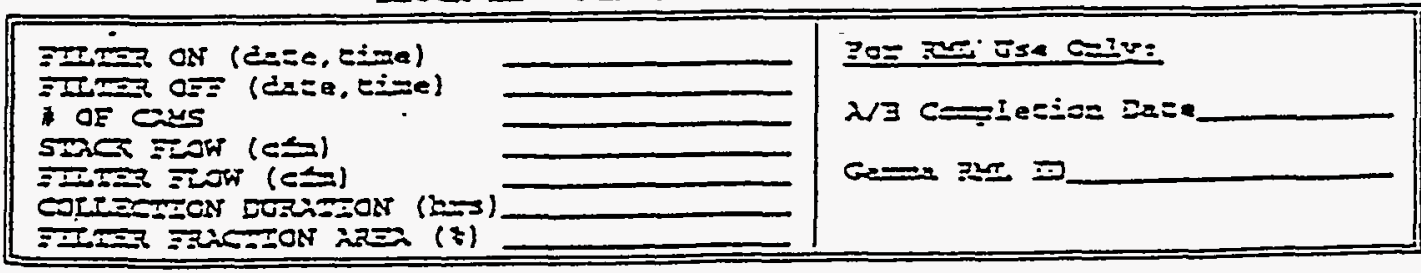

RECENO EY DATETME. CHALN OF CUSTOOY NUMEET(S) REPOFT OUE DAE COMMEVTs 


\begin{tabular}{|l|c|}
\hline EG\&G.WAHO, INC. & TITLE: HAZARDOUS MATERILIS CONTROLS IN RADIOACTTVE \\
COMTPANY & \multicolumn{2}{|c|}{ MATERIAL MLNAGEMENT AREAS (RMMA) } \\
PROCEDURES MANUAL & NUMBER: 8.16 C DATE: \\
\hline
\end{tabular}

\section{Appendix TV (Page 1 of 2)}

\section{Acceptable Analysis Techniques}

The Performance Objective ( $p$ 7-8) (Ref. 4.1) provides guidance for acceptable survey techniques to certify that the material does not need to be controlled as radioactive or mixed waste. In part, it says:

"All procedures shall be appropriate for the radionuclides to be detected. The radionuclides of concern shall be part of the decision process for selecting the appropriate detection techriques and instruments. Radioassay techriques can only be used for determining a waste is not radioactive if they are capable of measuring the natural background in a virgin sample of the material being assayed."

"Survey and radioassay techniques and instrumentation shall be representative of up-to-date technologies reasonably available. Extraordinary techniques, such as counting samples in a radiation detector for unreasonably extended periods, are not required, as long as appropriate and necessary detection limits are achieved."

For EG\&G Idaho, this will be considered satisfied if:

1. The measurement standard deviation $\sigma_{m}$ for the nuclide combination of interest is less than 0.6 of the background envelope $E_{B}$ (discussed in Appendix $V$ ). The decision level $L_{d}$ shall be taken as the larger of $E_{B}$ or $1.65 \sigma_{m}$. Thus the confidence of not declaring a radioactive item clean (generating a false negative) is $5 \%$ at $A=I_{d}-1.65 \sigma_{m}$ (nearly zero), $50 \%$ at $A=L_{d}$ (the background envelope), and $95 \%$ at $A=L_{d}+1.65 \sigma_{m}$ (less than twice the background envelope).

2. If attaining this standard deviation is not possible using "survey and radioassay techniques and instrumentation. . . representative of up-to-date technologies", then the standard deviations associated with "up-to-date technologies" shall be acceptable.

3. If the background envelope is based on measurements with the proposed system, absolute accuracy [i.e. National Institute of Standards and Technology (NIST) traceability] of the measurement is not required. If it is based on other measurement systems, the relative accuracy of the screening measurements shall support the accuracies required for the Go/No Go decisions being made. Quality control measurements to show that detector performance is not degrading must be routinely performed as stated in a laboratory procedure. 
EG\&G DAAHO, INC. COMIPANY PROCEDURES MANUAL
TITLE:
HAZARDOUS MLATERIALS CONTROLS IN R
MATERIAL MIANAGEMENT AREAS (RIMULA)

NUMBER: 8.16 DATE:

\section{Appendix IV (Page 2 of 2)}

The analyses described in Appendix III have been approved as part of the conditions for lifting the Hazardous Waste Shipping Moratorium. Preference should be given to using these procedures if they are applicable. For materials which do not fit the approved analyses protocols, special protocols may be proposed.

Other protocols and measurements to satisfy the above requirements shall be identified by waste generators or analysis laboratories. These protocols may be used after they are approved by the EG\&G Radiation Protection Cognizant Professional and submitted to the DOE-ID Manager of the Waste Management Operations Branch for comment. Lack of comment in 2 weeks shall be interpreted as concurrence.

A draft of the package shall be submitted to the Radiological Engineering Unit, which is to provide additional guidance on the format. When ready for consideration for approval, 5 copies of the package shall be provided for review and recommendation to the EG\&G Idaho Radiation Protection Cognizant Professional for approval.

The submittal should consist of attachments and a narrative description of the protocol which: -Identifies the class of radionuclides for which the procedure is applicable,

-Identifies and discuss the measurement technique,

-Describes training and/or certification of analysts,

-Addresses the quality control program for the facility and calibration techniques of the instruments (quality control shall include, as a minimum, measurements of background and response to appropriate check sources at prescribed intervals), and

-Walks the reader through the relevant procedures supplied as attachments.

The attachments shall include a table of contents for the facility procedures manual, and the relevant procedures which guide the analysts through:

- The critical aspects of the analysis,

- The decision process as to whether DOE-added radioactivity has been found in the sample, and

- Completion of the EG\&G-1075 form. 


\begin{tabular}{|c|c|c|}
\hline $.16 \mathrm{~B}$ & $9 / 27 / 94$ & Page 18 of 20 \\
\hline $\begin{array}{l}\text { EG\&G DAHO, INC. } \\
\text { COMIPANY }\end{array}$ & $\begin{array}{l}\text { TIILE: BAZARDOUS MS } \\
\text { MATERIAL MAN }\end{array}$ & $\begin{array}{l}\text { OLS IN RADIOACTIVE } \\
\text { (RMIIIA) }\end{array}$ \\
\hline PROCEDURES MANUAL & NUMBER: 8.16 & \\
\hline
\end{tabular}

\section{Appendix V (Page 1 of 2) \\ Establishing the Background Envelope for a Material}

Inherent in the process of showing that no DOE activities have added any radioactivity to waste is establishing an amount of radioactivity that may be found in virgin material.

Virgin materials will typically contain various amounts of radioactivity. The specific activity $\mathrm{A}(\mathrm{pCi} / \mathrm{g})$ of the virgin material will not be a single value and is often described by a $\log$-normal distribution $f(A)$ with a geometric mean $A_{0}$ and a geometric standard deviation $s_{g}$.

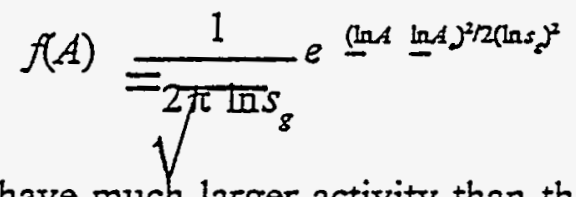

Thus, occasional samples will have much larger activity than the average. This distribution has been demonstrated for fallout strontium in bone $e^{1}$ and nuclides in soil where the activity has a relative geometric standard deviation of $1.76 .^{2}$ The average geometric standard deviation for 15 different distributions was 1.59 , the value which will be used at the INEL.

We define the background envelope $E_{B}$ as a set of survey specific values proportional to activity that bound those present in the virgin material. The background envelope value shall be established as the product of the geometric mean and the geometric standard deviation $s_{\mathrm{g}}$ of the distribution of activities in samples of the virgin material raised to the 1.65 power. Thus the confidence of not declaring a virgin item radioactive (generating a false positive) assuming a measurement without uncertainty is about $95 \%$.

The basis of the background envelope used for different materials shall be documented with an Engineering Design File (EDF) or Company Procedure (CP). The background envelope used to determine if a sample of hazardous waste is radioactive shall be identified on the EG\&G-1075 form and referenced accordingly.

To determine the background envelope, the following procedure shall be followed.

${ }^{1}$ See Fig 6.2-7 and p 280 - 286 of "CRC Handbook of Radiation Measurement and Protection, Volume II, Biological and Mathematical Information." A. Brodsky, Ed. (1982) for more information.

2 "1976 Environmental Monitoring Program Report for Idaho National Engineering Laboratory Site." May 1977 DO-12082 (76), and Appendix VI. 


\begin{tabular}{|l|cc|}
\hline EG\&G DAEO, INC. & TITLE: HAZARDOUS MATERLALS CONTROLS IN RADIOACTIVE \\
COMOPANY & \multicolumn{2}{|c|}{ MATERIAL MANAGEIVENT AREAS (RMMA) } \\
PROCEDURES MANUAL & NUMBER: $8.16 \quad$ DATE: \\
\hline
\end{tabular}

\section{Appendix V (Page 2 of 2)}

1. Virgin samples of materials will be used to establish a non-zero background envelope. One or more samples will be counted using a measurement standard deviation smaller than 0.6 of the measurement or $1 \mathrm{pCi} / g m$ for ${ }^{137} \mathrm{Cs}$ for gamma spectrometry measurements or the nuclide of interest for other measurements. The background envelope shall be initially defined at 2.15 times the measured activity. This initial choice based on one measurement assumes that the one value is at the geometric mean and that the activity in the material has a relative geometric standard deviation of 1.59 (Note that $1.59^{1.65}=2.15$ ).

2. This envelope may be refined by counting four additional samples using a measurement standard deviation no larger than one-third of the initial measurement value. These results shall be used to evaluate a geometric mean and standard deviation. The envelope shall be reestablished at 2.15 times that mean.

3. If it is necessary to further refine the background envelope, measurements of five additional samples of virgin material ${ }^{3}$ of that class would be taken using a measurement standard deviation no larger than one-third of the standard deviation of the samples counted in step 2. These results shall be used to evaluate a geometric mean and a geometric standard deviation. The envelope shall be reestablished as the product of the new measured geometric mean and the measured geometric standard deviation of the sample activities raised to the 1.65 power.

Appendix VI presents information on background activity in soils local to the INEL and establishes the associated activity background envelope for soil-like materials.

${ }^{3}$ The term sample does not refer to $2 n$ aliquot of the same container of virgin material, but rather refers to samples of similar material of different origins. It will be extremely easy to obtain samples from materials from the same source, and if done they will probably have a variation smaller than the actual variation of similar materials. 


\begin{tabular}{|c|c|}
\hline $\begin{array}{l}\text { EG\&G IDAE } \\
\text { COMPANY }\end{array}$ & $\begin{array}{l}\text { TTILE: HAZARDOUS MATERIALS CONTROLS IN RADIOACTI } \\
\text { MATERLAL MANAGEMENT AREAS (RMMLA) }\end{array}$ \\
\hline URES MAYUAL & BBER: 8.16 \\
\hline
\end{tabular}

\section{Appendix VI}

\section{Background Envelope for Soil}

Table 1 presents measured activities in soil local to INEL. From one reference, a range of measured values is specified for a limited number of samples. The footnote from the other reference describes the variability for a much larger group of measurements. The background envelope in column 6 represents the upper end of the distribution of background activities for soil and is 2.15 times the average value (usually keeping only one significant digit). This table may be extended by EG\&G Idaho to other nuclides using credible sources (e.g., UNSCEAR, NCRP, INEL Environmental Monitoring reports) or documented measurements.

Table 1 : Activities in soil local to INEL.

\begin{tabular}{llllll} 
Isotope & $\begin{array}{l}\text { Mean } \\
\text { pCi/g }\end{array}$ & $\begin{array}{l}\text { Range } \\
\text { pCi/g }\end{array}$ & $\begin{array}{l}\text { Number } \\
\text { Samples }\end{array}$ & $\begin{array}{l}\text { Ref. } \\
\text { Cs-137 }\end{array}$ & $\begin{array}{l}\text { Envelope } \\
\text { pCi/g }\end{array}$ \\
\hline Sr-90 & 1.0 & $0.66-2.05$ & 10 & 1 & 2 \\
K-40 & 0.6 & $0.20-1.0$ & 10 & 1 & 1.3 \\
Pu-238 & 15. & $11.1-20.0$ & 10 & 1 & 30 \\
Pu-239/240 & 0.0015 & $0-0.004$ & 10 & 1 & 0.003 \\
Th-232 \# & 0.020 & $0.008-0.041$ & 10 & 1 & 0.04 \\
Th-232 \# & 1.35 & $0.76-1.86$ & 10 & 1 & \\
Th series \# $(6 \alpha, 4 \beta)$ & 1.34 & $*$ & 114 & 2 & 3 \\
U-238 $\frac{}{\pi}$ & 13 & $*$ & & 2 & $18 \alpha, 12 \beta$ \\
U series \# $(8 \alpha, 6 \beta)$ & 1.52 & $*$ & & 2 & 3 \\
Total $\alpha$ & 21 & $*$ & & & $26 \alpha, 20 \beta$ \\
Total $\beta$ & & & & & 74 \\
\hline
\end{tabular}

* Reference 2 states (p 24) "Soll sample data even from undisturbed locations are highly variable. For instance, for $95 \%$ of all offsite soil concentrations of Cs-137, the highest concentration was nine times the lowest. (Two standard geometric deviations of individuals was 3.1.) The other radionuclides have similar concentration ranges."

\# Secular equilibrium assumed without account " $\mathrm{H}$. radon diffusion.

References:

1. Richard.L. Dickson. "Radiation Exposure Rates and Radionuclide Concentrations in Soil around the Argonne National Laborator; -West Site." March 1986. DOE/ID-12106.

2. "1976 Environmental Monitoring Program Report for Idaho National Engineering Laboratory Site." May 1977 DO-12082 (76) 


\section{Appendix B}

Callculation of Total and Peak Area Efficiency Using the Monte Carlo Electron and Photon Transport Code CYLTRAN 


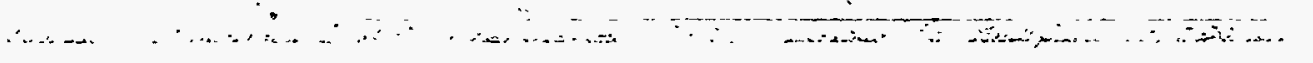




\title{
Appendix B
}

\section{Calculation of Total and Peak Area Efficiency Using the Monte Carlo Electron and Photon Transport Code CYLTRAN}

\author{
R. G. Helmer and R. J. Gehrke
}

The program CYLTRAN (see Reference 7 of text) was used to model the counting efficiency for the geometry shown in Figure 7 of the text. Since the CYLTRAN code was written to address cylindrical geometries, the lead brick, as shown in Figure 7, was simulated by a cylinder in order to use the CYLTRAN code. Further, the source must be represented as input to CYLTRAN as an infinitely thin disk. These CYLTRAN requirements suggested removing a portion of the ends of the lead brick where attenuation is significant due to its distance from the detector so that cylindrical geometry could be achieved without serious impact to the modeled problem. For example, the $661-\mathrm{keV} \gamma$ ray emitted from a ${ }^{137} \mathrm{Cs}$ point source located $7.62 \mathrm{~cm}$ ( $3 \mathrm{in}$.) from the center of the brick and $6.35 \mathrm{~cm}(2.5 \mathrm{in}$.) from the outer edge of the $\mathrm{NaI}(\mathrm{Tl})$ crystal will be attenuated by $99.975 \%$ before reaching the crystal. In other words, the detector is insensitive to any ${ }^{137} \mathrm{Cs}$ activity located in the end portions of the lead brick.

The geometry being modeled is shown in Figure 8. The detector is located within the bottom hole, and the radioactive contamination is distributed homogeneously in the lead surrounding the detector. The efficiency is deduced from a number of thin washer-shaped source calculations. The efficiency for each washer shaped slice is deduced by subtracting the effect of the smaller hole-sized slice $(2.859 \mathrm{~cm}$ in diameter) from that of the larger-sized circle $(5.08 \mathrm{~cm}$ in diameter), extending to the edge of the brick. In this case, the source planes pass through the detector. The efficiency for each washer-shaped disk is calculated by the following method.

For a given slice, the CYLTRAN code computes the average efficiency for the slice. Hence, $\epsilon_{\text {is }}=$ the average efficiency for the small circular source,

and

$\epsilon_{\mathrm{il}}=$ the average efficiency for the large circular source

where

$\mathbf{s}=$ parameter associated with the small geometry

$1=$ parameter associated with the large geometry

$r$ = parameter associated with the ring geometry.

The subscript $i$ represents the slice position (i.e., $1,2, \ldots$ ). The efficiency $\epsilon_{\text {ir }}$ for a washershaped source is calculated from the total histories $\mathrm{H}=\mathrm{H}_{\mathrm{l}}$, the total histories with $\gamma$ rays originating from anywhere within the area of the large circular source, $\mathrm{H}_{s}$, the histories with $\gamma$ 's 
originating from the area corresponding to the smaller circular source, $\mathrm{P}(\mathrm{t})$, the counts recorded in the total spectrum, and $\mathrm{P}(\mathrm{p})$, the counts recorded in the $661-\mathrm{keV}$ peak. The $\mathrm{H}_{1}$ histories are related to the $\mathrm{H}_{\mathrm{s}}$ histories by the relative areas of the small to large source circles:

$H_{i s}=H_{i l}\left(A_{i j} / A_{i l}\right)=H_{i}\left(R_{i s} / R_{i l}\right)^{2-}$

since $A_{i s}=\Pi R_{i s}^{2}$, and $A_{i l}=\prod R_{i l}^{2}$ for a circular source at position $i$.

The histories recorded in the washer-shaped source are:

$\mathrm{H}_{\mathrm{ir}}=\mathrm{H}_{\mathrm{il}}-\mathrm{H}_{\mathrm{is}}=\mathrm{H}-\mathrm{H}\left(\mathrm{R}_{\mathrm{is}} / \mathrm{R}_{\mathrm{il}}\right)^{2}=\mathrm{H}\left[1-\left(\mathrm{R}_{\mathrm{is}} / \mathrm{R}_{\mathrm{il}}\right)^{2}\right]$.

Further,

$P_{\mathrm{il}}=\left(\epsilon_{\mathrm{il}}\right)\left(\mathrm{H}_{\mathrm{il}}\right) / 100$,

and

$P_{\text {is }}=\left(\epsilon_{\mathrm{is}}\right)\left(\mathrm{H}_{\mathrm{is}}\right) / 100=\left(\epsilon_{\mathrm{is}}\right)(\mathrm{H})\left(\mathrm{R}_{\mathrm{is}} / \mathrm{R}_{\mathrm{il}}\right)^{2} / 100$

where the subscripts follow the same nomenclature as specified above (e.g., $P_{i l}(t)$ are the number of counts in the total spectrum for a large circular source at position i).

$P_{i r}=P_{i l}-P_{i s}=\left(\epsilon_{i l}\right)(H) / 100-\left(\epsilon_{i s}\right)(H)\left(R_{i s} / R_{i l}\right)^{2} / 100$

$P_{i r}=P_{i l}-P_{i s}=(H) / 100\left[\epsilon_{i l}-\epsilon_{i s}\left(R_{i s} / R_{i l}\right)^{2}\right]^{.}$

Then,

$\epsilon_{\mathrm{ir}}=\left(\mathrm{P}_{\mathrm{ir}}\right)(100) / \mathrm{H}_{\mathrm{ir}}$

Hence,

$\epsilon_{\mathrm{ir}}=\left[\epsilon_{\mathrm{il}}-\epsilon_{\mathrm{is}}\left(\mathrm{R}_{\mathrm{is}} / \mathrm{R}_{\mathrm{il}}\right)^{2}\right] /\left[1-\left(\mathrm{R}_{\mathrm{is}} / \mathrm{R}_{\mathrm{il}}\right)^{2}\right]$ for ring in position $\mathrm{i}$.

To calculate the efficiency, $\epsilon_{\mathrm{r}}$ for the entire lead brick with bottom hole, the average of the efficiencies, $\epsilon_{\mathrm{il}}$, associated with the large circular areas beneath the bottom hole are averaged, and the iciencies, $\epsilon_{\mathrm{ir}}$ associated with the ring areas are averaged. These averages are combined by a weighted average with the relative masses of these two regions used as the weights. The efficiencies for lead brick geometry (activity uniformly distributed throughout the brick) for the total spectrum, $\epsilon(t)$, and for the $661-\mathrm{keV}$ peak region, $\epsilon_{\mathrm{p}}$, are calculated in this manner to be $0.797 \%$ and $0.145 \%$, respectively. After the modeling process, it was learned that a 0.125 -in. spacer of foam lies between the teflon reflector adjacent to the flat end of the $\mathrm{NaI}(\mathrm{Tl})$ and the aluminum cover. However, this spacer has negligible effect upon the efficiency values, $\epsilon(t)$ and $\epsilon(p)$, for a radioactive source of ${ }^{137} \mathrm{Cs}$ uniformly distributed throughout the lead brick. 
To validate the Monte Carlo calculations, the efficiency values, $\epsilon(t)$ and $\epsilon(p)$, were modeled for a geometry that could be checked with a measured value. The geometry chosen was for a 0.4 $\mathrm{cm}$ source of ${ }^{137} \mathrm{Cs}$ against the end of the $\mathrm{NaI}(\mathrm{TI})$ detector surrounded by lead. For this geometry, it is important that all of the physical components comprising the detector are known and that their physical dimensions are accurately known. Therefore, it was necessary to model and calculate the ${ }^{137} \mathrm{Cs}$ efficiency for point source geometry with the source against the end case of the NaI(TI) detector (the foam spacer between the aluminum window and the front face of the NaI(TI) crystal was included in the model). The efficiencies obtained from the Monte Carlo calculation were:

$\epsilon(t)=12.4 \%$

and

$\epsilon(p)=2.9 \%$

compared to the measured values of

$\epsilon(\mathrm{t})=13.7 \%$

and

$\epsilon(\mathrm{p})=2.4 \%$. 


\section{Appendix C}

\section{Instructions for the Operation of the Volumetric}

Lead Brick Contamination Assay Spectrometer 


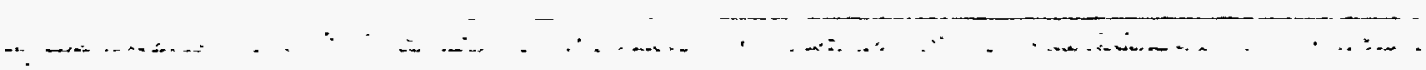

. 


\section{Appendix C}

\section{Instructions for the Operation of the Volumetric Lead Brick Contamination Assay Spectrometer}

\section{C.1 Energize the Assay System from a Cold Start}

1. Make sure that all electrical connections, including the computer interface, are securely connected. Set up the lead shielding as shown in Figures 1 and 2.

2. Make sure that the high-voltage bias potentiometer is set to zero.

3. Turn on the power to the NOMAD.

WARNING: The NOMAD must be powered on before you turn on the PC so that the PC is aware of the NOMAD's presence.

4. Turn on the power to the PC.

5. Ensure that the positive high-voltage bias light on the NOMAD console is on.

6. Use the PC mouse arrow to double click on the MAESTRO icon (WINDOWS).

7. Use the PC mouse arrow to click on the Acquire "pull-down" menu.

8. Use the PC mouse to click on the $92 \mathrm{X}$ Control. This causes a new display for setting the high-voltage bias, gain, pole zero, and the time constant.

9. Set the gain at $40 \mathrm{X}$ and the fine gain at 0.9 (effective gain $=36$ ).

10. Set the time constant to "short."

11. Verify that the high-voltage potentiometer is at zero volts.

12. Click the box that turns on the high voltage. (Move mouse away from this position.)

13. Increase the voltage by turning the potentiometer slowly to the operating voltage required by the $\mathrm{NaI}(\mathrm{TI}) / \mathrm{PMT}$ (see display - only nearest 100 volts displayed). Prior to measuring the plateau curve, use the manufacturer's recommended high-voltage bias. Afterwards, use the setting determined from the plateau curve.

WARNING: The high voltage should be increased gradually from zero volts.

14. Lock the potentiometer in place. 
15. Click on the "esc" box.

Allow approximately 15 minutes for the system to warm up and equilibrate to avoid electronic drift.

\section{C.2 Measure Plateau Curve}

1. Follow the instructions for energizing the assay system from a cold start. Set the voltage in step 13 to 200 volts. Allow the system to warm up and equilibrate.

2. Disassemble lead shielding, being careful not to drop or otherwise damage the NaI(TI)/PMT. Use protective gloves to avoid contamination of hands with lead or lead oxide.

Warning: Do not set a brick on its edge (2-in. by 4-in. side) near the edge of the table or counter.

3. Place the $10.2-\mathrm{nCi}{ }^{137} \mathrm{Cs}$ calibration source that is on a stainless steel disk into the bottom of the well in the lead brick. Center the source as well as possible with the string side down. (The string is taped to the back side of the source to facilitate its removal from the hole.)

4. Place the NaI(TI)/PMT in place over the ${ }^{137} \mathrm{Cs}$ source and enclose the $\mathrm{NaI}(\mathrm{TI}) / \mathrm{PMT}$ in the machined lead bricks. Align the machined circular groove in the upright brick that holds the detector with the hole in the bottom horizontal brick.

NOTE: The ${ }^{137} \mathrm{Cs}$ source and lead bricks should not be moved until all data for the plateau curve have been collected.

5. Acquire a spectrum_for 300 seconds by clicking on the Acquire "pull-down" menu, entering 300 for the live time, and clicking on "ok."
a. Press Alt-2 to stop a previous spectrum from acquiring data.
b. Press Alt-3 to clear any previously acquired spectrum.
c. Press Alt-1 to initiate acquisition of a new spectrum.

The spectrum being acquired can be observed on the PC monitor when the counts are displayed in the log scale (see display pull-down menu).

6. Upon completion of the spectral acquisition, press Alt-5 to transfer the spectrum to the buffer. If a spectrum is already in the buffer, the computer will ask whether or not to save the buffer spectrum prior to transferring the spectrum in the MCB. Do not save the spectrum in the buffer.

7. Click on the buffer in the top right-hand corner of the display under "Display." 
The following instructions (\#8 through \#19) measure the total spectral counts in the ${ }^{137} \mathrm{Cs}$ spectrum:

8. Move the line marker to channel 4 of the spectrum.

9. Click on the region-of-interest (ROI) "pull-down" menu (Alt-R may also access the ROI "pulldown" menu).

10. Click on Clear All ( $\mathrm{C}$ on the keyboard will also work).

11. Click on the ROI "pull-down" menu.

12. Click on Mark ( $M$ on the keyboard will also work).

13. Click on the ROI "pull-down" menu.

14. Click on Begin (B on the keyboard will also work).

15. Move the line marker to channel 1,012 of the spectrum.

16. Click on the ROI "pull-down" menu.

17. Click on End ( $E$ on the keyboard will also work).

18. Click on the Calculate "pull-down" menu (Alt-C may also access the Calculate "pull-down menu).

19. Click on Sum ( $M$ on the keyboard will also work).

20. Record the sum in the lead brick volumetric contamination log book.

The following instructions (\#21 through \#26) will save a spectrum as a file in the LEADC directory as a .CHN type file (raw data):

21. Click on the File "pull-down" menu (Alt-F will also access file).

22. Click on Save ( $\mathrm{S}$ on the keyboard will also work).

23. Click on "[..]" to bring up the LEADC directory:

24. Click on the LEADC directory.

25. Move cursor to the file box, delete file, and replace with file name including the extension ".CHN". A spectrum ID protocol has been developed. "SMMDDYxx" is an eight-digit alphanumeric character consisting of system number (S), month (MM), date (DD), year (Y), and sequence number $(\mathrm{xx})$. 
26. Type answers to the questions asked, including the file number and a brief title and brick ID. number. The file will be stored in the LEADC directory.

27. Record the file name in the lead brick volumetric contamination log book.

28. Click on "Full" in the top right-hand corner of the display under "Display."

29. Use the PC mouse arrow to click on the Acquire "pull-down" menu.

30. Unlock the potentiometer and slowly increase the voltage 25 volts. Lock the potentiometer in place.

31. Repeat steps 4 through 21 until the voltage reaches a point 50 volts above the knee. Refer to Figure 3. DO NOT exceed 1,000 volts.

32. On completion of acquisition of the plateau curve data, plot the counts as a function of highvoltage bias on linear graph paper as shown in Figure 3. Identify the knee of the plateau and select the high-voltage bias, at which sequential counts should be made.

\section{C.3 Perform Energy Calibration of Assay System}

1. Disassemble lead shielding, being careful not to drop or otherwise damage the NaI(TI)/PMT. Use protective gloves when handling lead brick to avoid contamination of hands with lead or lead oxide.

Warning: Do not set a brick on its edge (the 2-in. by 4-in. side) near the edge of the table or counter.

2. Place the $10-\mathrm{nCi}^{137} \mathrm{Cs}$ source that is on a stainless steel disk into the bottom of the well in the lead brick. Center as well as possible with the string side down. (The string is taped to the back side of the source to facilitate its removal from the hole.)

3. Place the $\mathrm{NaI}(\mathrm{Tl}) / \mathrm{PMT}$ in place over the ${ }^{137} \mathrm{Cs}$ source and enclose the NaI(TI)/PMT in the machined lead bricks. Align the machined circular groove in the upright brick that holds the detector with the hole in the bottom horizontal brick.

4. Acquire a spectrum for 900 seconds by clicking on the Acquire "pull-down" menu, entering 900 for the live time, and clicking on "ok."

a. Press Alt-2 to stop a previous spectrum from acquiring data.

b. Press Alt-3 to clear any previously acquired spectrum.

c. Press Alt-1 to initiate acquisition of a new spectrum.

The spectrum being acquired can be observed on the PC monitor when the counts are displayed in the log scale (see display pull-down menu). 
5. Upon completion of the spectral acquisition, press Alt-5 to transfer the spectrum to the buffer. If a spectrum is already in the buffer, the computer will ask whether or not to save the buffer spectrum prior to transferring the spectrum in the MCB. Do not save the spectrum in the buffer.

6. Click on the Buffer in the top right-hand corner of the display under "Display."

The following instructions (\#7 through \#19) measure the total spectral counts in the ${ }^{137} \mathrm{Cs}$ spectrum:

7. Move the line marker to channel 4 of the spectrum.

8. Click on the ROI "pull-down" menu (Alt-R may also access the ROI "pull-down" menu).

9. Click on Clear All (C on the keyboard will also work).

10. Click on the ROI "pull-down" menu.

11. Click on Mark (M on the keyboard will also work).

12. Click on the ROI "pull-down" menu.

13. Click on Begin (B on the keyboard will also work).

14. Move the line marker to just below the highest channel ( channel 1,020$)$.

15. Click on the ROI "pull-down" menu.

16. Click on End (E on the keyboard will also work).

17. Click on the Calculate "pull-down" menu (Alt-C may also access the Calculate "pull-down menu).

18. Click on Sum ( $\mathrm{M}$ on the keyboard will also work).

19. Record the sum in the lead brick volumetric contamination log book.

The following instructions (\#20 through \#43) calibrate the energy scale in units of keV:

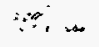

20. Move the line marker to below channel 10 of the spectrum.

21. Click on Expand in the top right-hand corner of the display.

22. Using Figure 4 as an aide, locate the $75-\mathrm{kev} \mathrm{Pb} \mathrm{Kx}$ ray ( channel 30) and the 661.6-kev $\gamma$ ray ( channel 235). Note: The lowest energy peak in the spectrum at $32-\mathrm{keV}$ is the $\mathrm{K} \mathrm{X}$-ray peak from the ${ }^{137} \mathrm{Cs}$ decay. 
23. Click on the ROI "pull-down" menu.

24. Click on Clear All.

25. Advance the line marker using the mouse to a suitable background position just below the $75-\mathrm{keV}$ peak. Allow for some drift in the gain, which at $661 \mathrm{keV}$ may be a drift of $5 \mathrm{keV}$ over the course of a day.

26. Click on the ROI "pull-down" menu).

27. Click on "Mark."

28. Click on the ROI "pull-down" menu.

29. Click on "Begin."

30. Advance the line marker using the mouse to a suitable background position just above the 75 $\mathrm{keV}$ peak.

31. Click on the ROI "pull-down" menu.

32. Click on "End."

33. Move line marker to center of $75-\mathrm{keV}$ peak.

34. Click on the Calculate "pull-down" menu.

35. Click on "Calibrate" ( $\mathrm{C}$ on the keyboard will also work).

36. Enter the energy of the $\mathrm{Pb} \mathrm{K}$ x-ray $(75 \mathrm{keV})$.

37. Repeat steps 26 through 32 but with the $661-\mathrm{keV}$ peak. Record the start and end channel positions in the count log for use in the analysis of lead bricks to be counted (e.g., 210, 262).

38. Move the line marker to the center of the $661-\mathrm{keV}$ peak.

39. Click on the Calculate "pull-down" menu.

40. Click on Calibrate.

41. Enter the energy of the ${ }^{137} \mathrm{Cs} \gamma$ ray $(661.63 \mathrm{keV})$.

42. Enter $\mathrm{keV}$ as the units for the energy scale.

43. Verify the gain and zero by selecting peaks in the spectrum and moving the line marker to those positions. 
The following instructions (\#44 through \#54) measure the gross and net counts in the 661-keV peak:

44. Set line marker to a channel known to be just below the $661-\mathrm{keV}$ peak; see step 37 of most recent energy calibration count (channel 210).

45. Click on the ROI "pull-down" menu.

46. Click on Clear All.

47. Click on the ROI "pull-down" menu.

48. Click on Mark.

49. Click on ROI "pull-down" menu.

50. Click on Begin.

51. Move the line marker to a channel known to be just above the $661-\mathrm{keV}$ peak; see step 37 of most recent energy calibration count (channel 262).

52. Click on the Calculate "pull-down" menu.

53. Click on peak information ( $\mathrm{A}$ on the keyboard will also work).

54. Record the 661-keV peak channel position and the gross and net peak area in the lead brick volumetric contamination log book.

The following instructions (\#55 through \#61) will save a spectrum as a file in the LEADC directory as a .CHN type file (raw data):

55. Click on the File "pull-down" menu (Alt-F will also access file).

56. Click on Save (S on the keyboard will also work).

57. Click on "[..]" to bring up the LEADC directory.

58. Click on the LEADC directory.

59. Move cursor to the file box, delete file, and replace with file name including the extension ".CHN". A spectrum ID protocol has been developed. "SMMDDYxx" is an eight-digit alphanumeric character consisting of system number (S), month (MM), date (DD), year (Y), and sequence number $(\mathrm{xx})$.

60. Type the answers to the questions asked, including the file number and a brief title and brick ID. number. The file will be stored in the LEADC directory.

61. Click on "Full" and "MCB" under "Display." 


\section{C.4 Assay of a Potentially Contaminated Lead Brick}

The following instructions (\#1 through \#4) acquire a spectrum of a sample lead brick:

1. Remove one side of the lead shielding enclosing the $\mathrm{NaI}(\mathrm{Tl})$ detector, being careful not to drop or otherwise damage the NaI(TI)/PMT. Slide the NaI(TI) detector out of the hole and move it with its brick to the side.

2. Remove the ${ }^{137} \mathrm{Cs}$ source, if present, from the bottom of the well in the lead brick to be assayed or insert lead brick to be assayed.

Warning: Either turn the lead brick upside down to remove the source or remove it by using the string that is attached to it.

3. Place the NaI(TI)/PMT in the machined hole in the brick and enclose sides with the machined lead bricks.

4. Acquire a spectrum for 900 seconds (or other selected count time).

a. Press Alt-2 to stop a previous spectrum from acquiring data.

b. Press Alt-3 to clear any previously acquired spectrum.

c. Press Alt-1 to initiate acquisition of a new spectrum.

The following instruction transfers the spectrum to the buffer:

5. Upon completion of the spectral acquisition, press Alt-5 to transfer the spectrum to the buffer.

The following instructions (\#6 through \#19) measure the total spectral counts in a sample lead brick:

6. Click on the Buffer in the top right-hand corner of the display under "Display."

7. Set the line marker to channel 4.

8. Click on the ROI "pull-down" menu.

9. Click on Clear All.

10. Click on the ROI "pull-down" menu.

11. Click on Mark.

12. Click on the ROI "pull-down" menu.

13. Click on Begin. 
14. Move the line marker to channel 1,012 .

15. Click on the ROI "pull-down" menu. .

16. Click on End.

17. Click on the Calculate "pull-down" menu.

18. Click on Sum.

19. Record the sum in the lead brick volumetric contamination log book.

The following instructions (\#20 through \#30) measure the gross and net counts in the 661-keV region of a spectrum from a sample lead brick:

20. Set the line marker to a channel known to be just below the $661-\mathrm{keV}$ peak (channel 210).

21. Click on the ROI "pull-down" menu.

22. Click on Clear All.

23. Click on the ROI "pull-down" menu.

24. Click on Mark.

25. Click on ROI "pull-down" menu.

26. Click on Begin.

27. Move the line marker to a channel known to be just above the $661-\mathrm{keV}$ peak (channel 262).

28. Click on the Calculate "pull-down" menu.

29. Click on peak information.

30. Record the $661-\mathrm{keV}$ peak channel position and the gross and net peak area in the lead brick volumetric contamination log book.

The following instructions (\#31 through \#34) save a sample spectrum as a file in the LEADC directory as a .CHN file (raw data):

31. Click on the File "pull-down" menu (Alt-F will also access the File "pull-down" menu).

32. Click on Save. (You will be in the LEADC directory.)

33. Move cursor to the file box, delete *, type in file name (including the extension .CHN), and press enter. 
34. Provide a brief title (brick ID number).

35. Click on MCB and proceed to the analysis of the next brick.

Note: An energy calibration count should be acquired after counting five bricks or if the spectrometer has sat idle for more than 2 hours. The new energy calibration count should be used to reestablish the ROIs surrounding the $661-\mathrm{keV}$ peak.

\section{C.5 Quality Control Charts}

The following quality control charts are recommended to be kept by the operator whenever lead bricks are to be screened for contamination:

1. The number of spectral counts in a known "blank" lead brick as a function of time and location of measurements.

2. The high-voltage bias setting as a function of time and location for each electronic configuration [i.e., $\mathrm{NaI}(\mathrm{Tl})$, NOMAD system, amplifier setting, and lower-level discriminator].

\section{C.6 System Shutdown}

1. Set Display to MCB.

2. Click on Acquire "pull-down" menu.

3. Click on the $92 \mathrm{X}$ Control.

4. Unlock potentiometer and slowly decrease operating voltage to zero.

5. Verify that the high-voltage bias potentiometer is at zero volts.

6. Click the box that turns off the high voltage.

7. Click on escape.

8. Click on File "pull-down" menu.

9. Click on Exit.

10. Turn off power to the PC.

11. Turn off power to the NOMAD. 
Appendix D

\section{Student t Table}





\title{
Appendix D
}

\section{Student t Table}

\author{
Student's t-Distribution
}

PERCENTAGE POINTS..STUDENTS $t$-DISTRIBUTION

\begin{tabular}{|c|c|c|c|c|c|c|c|c|}
\hline$n$ & .60 & .75 & .90 & .95 & .975 & .99 & .995 & .9995 \\
\hline 1 & .325 & 1.000 & 3.078 & 6.314 & 12.706 & 31.821 & 63.657 & 636.619 \\
\hline 2 & .289 & .816 & 1.886 & 2.920 & 4.303 & 6.965 & 9.925 & 31.598 \\
\hline 3 & .277 & .765 & 1.638 & 2.353 & 3.182 & 4.541 & 5.841 & 12.924 \\
\hline 4 & .271 & .741 & 1.533 & 2.132 & 2.776 & 3.747 & 4.604 & 8.610 \\
\hline 5 & .267 & .727 & 1.476 & 2.015 & 2.571 & 3.365 & 4.032 & 6.869 \\
\hline 6 & .265 & .718 & 1.440 & 1.943 & $2.44 \bar{T}$ & $3.1 \pm 3$ & 3.707 & 5.959 \\
\hline 7 & .263 & .711 & 1.415 & 1.895 & 2.365 & 2.998 & 3.499 & 5.408 \\
\hline 8 & .262 & .706 & 1.397 & 1.860 & 2.306 & 2.896 & 3.355 & 5.041 \\
\hline 9 & .261 & .703 & 1.383 & 1.833 & 2.262 & 2.821 & 3.250 & 4.781 \\
\hline 10 & .260 & .700 & 1.372 & 1.812 & $2: 228$ & 2.764 & 3.169 & 4.587 \\
\hline 11 & .260 & .697 & 1.363 & 1.796 & 2.201 & 2.718 & 3.106 & $4 . \dot{\$} 37$ \\
\hline 12 & .259 & .695 & 1.356 & 1.782 & 2.179 & 2.681 & 3.055 & 4.318 \\
\hline 13 & .259 & .694 & 1.350 & 1.771 & 2.160 & 2.650 & 3.012 & 4.221 \\
\hline 14 & .258 & .692 & 1.345 & 1.761 & 2.145 & 2.624 & 2.977 & 4.140 \\
\hline 15 & .258 & .691 & 1.341 & 1.753 & 2.131 & 2.602 & 2.947 & 4.073 \\
\hline 16 & .258 & .690 & 1.337 & 1.746 & 2.120 & 2.583 & 2.921 & 4.015 \\
\hline 17 & .257 & .689 & 1.333 & 1.740 & 2.110 & 2.567 & 2.898 & 3.965 \\
\hline 18 & .257 & .688 & 1.330 & 1.734 & 2.101 & 2.552 & 2.878 & 3.922 \\
\hline 19 & .257 & .688 & 1.328 & 1.729 & 2.093 & 2.539 & 2.861 & 3.883 \\
\hline 20 & .257 & .687 & 1.325 & 1.725 & 2.086 & 2.528 & 2.845 & 3.850 \\
\hline 21 & .257 & .686 & 1.323 & 1.721 & 2.080 & 2.518 & 2.831 & 3.819 \\
\hline 22 & .256 & .686 & 1.321 & 1.717 & 2.074 & 2.508 & 2.819 & 3.792 \\
\hline 23 & .256 & .685 & 1.319 & 1.714 & 2.069 & 2.500 & 2.807 & 3.767 \\
\hline 24 & .256 & .685 & 1.318 & 1.711 & 2.064 & 2.492 & 2.797 & 3.745 \\
\hline 25 & .256 & .684 & 1.316 & 1.708 & 2.060 & 2.485 & 2.787 & 3.725 \\
\hline 26 & .256 & .684 & 1.315 & 1.706 & 2.056 & 2.479 & 2.779 & 3.707 \\
\hline 27 & .256 & .684 & 1.314 & 1.703 & 2.052 & 2.473 & 2.771 & 3.690 \\
\hline 28 & .256 & .683 & 1.313 & 1.701 & 2.048 & 2.467 & 2.763 & 3.674 \\
\hline 29 & .256 & . 683 & 1.311 & 1.699 & 2.045 & 2.462 & 2.756 & 3.659 \\
\hline 30 & .256 & .683 & 1.310 & 1.697 & 2.042 & 2.457 & 2.750 & 3.646 \\
\hline 40 & .255 & .681 & 1.303 & 1.684 & 2.021 & 2.423 & 2.704 & 3.551 \\
\hline 60 & .254 & .679 & 1.296 & 1.671 & 2.000 & 2.390 & 2.660 & 3.460 \\
\hline 120 & .254 & .677 & 1.289 & 1.658 & 1.980 & 2.358 & 2.617 & 3.373 \\
\hline$\infty$ & .253 & .674 & 1.282 & 1.645 & 1.960 & 2.326 & 2.576 & 3.291 \\
\hline
\end{tabular}

